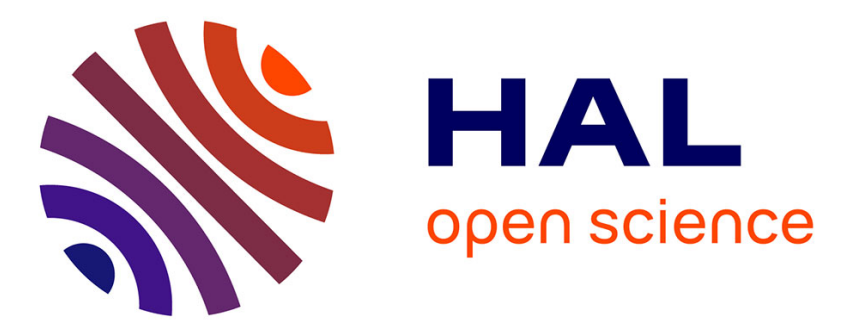

\title{
Protective role of the mitochondrial fusion protein OPA1 in hypertension
}

Pauline Robert, Phuc Minh Chau Nguyen, Alexis Richard, Céline Grenier, Arnaud Chevrollier, Mathilde Munier, Linda Grimaud, Coralyne Proux, Tristan Champin, Eric Lelièvre, et al.

\section{To cite this version:}

Pauline Robert, Phuc Minh Chau Nguyen, Alexis Richard, Céline Grenier, Arnaud Chevrollier, et al.. Protective role of the mitochondrial fusion protein OPA1 in hypertension. FASEB Journal, 2021, 35, 10.1096/fj.202000238rrr . hal-03379614

\section{HAL Id: hal-03379614 https://hal.science/hal-03379614}

Submitted on 15 Oct 2021

HAL is a multi-disciplinary open access archive for the deposit and dissemination of scientific research documents, whether they are published or not. The documents may come from teaching and research institutions in France or abroad, or from public or private research centers.
L'archive ouverte pluridisciplinaire HAL, est destinée au dépôt et à la diffusion de documents scientifiques de niveau recherche, publiés ou non, émanant des établissements d'enseignement et de recherche français ou étrangers, des laboratoires publics ou privés. 


\title{
Protective role of the mitochondrial fusion protein OPA1 in hypertension
}

\author{
Pauline Robert $^{1,2,3}$ | Phuc Minh Chau Nguyen ${ }^{1,2,3}$ | Alexis Richard ${ }^{1,2,3}$ | \\ Céline Grenier $^{1,2,3}$ | Arnaud Chevrollier ${ }^{1,2,3}$ ｜ Mathilde Munier ${ }^{1,2,3}$ | Linda Grimaud ${ }^{1,2,3}$ \\ Coralyne Proux ${ }^{1,2,3}$ \\ Emilie Vessières ${ }^{1,2,3}$ \\ Tristan Champin ${ }^{1,2,3}$ \\ Eric Lelièvre ${ }^{1}$ \\ Emmanuelle Sarzi ${ }^{4}$ \\ Guys Lenaers ${ }^{1,2,3,5}$

Samir Henni $^{5}$ | Delphine Prunier ${ }^{1,2,3,5}$ \\ Céline Fassot ${ }^{1,2,3}$ \\ Daniel Henrion ${ }^{1,2,3,5}$ \\ | Pascal Reynier ${ }^{1,2,3,5}$ \\ | Laurent Loufrani ${ }^{1,2,3}$ (D)
}

\author{
${ }^{1}$ MITOVASC Institute and CARFI Facility, \\ University of Angers, Angers, France \\ ${ }^{2}$ UMR CNRS 6015, Angers, France \\ ${ }^{3}$ INSERM U1083, Angers, France \\ ${ }^{4}$ Institute for Neurosciences of \\ Montpellier-INSERM U1051, \\ Montpellier, France \\ ${ }^{5}$ University Hospital (CHU) of Angers, \\ Angers, France

\section{Correspondence} \\ Laurent Loufrani, MITOVASC, CNRS \\ UMR 6015, INSERM U1083, 3 rue Roger \\ Amsler, Angers 49045, France. \\ Email: laurent.loufrani@inserm.fr
}

\section{Funding information}

This work was supported by the Region Pays de la Loire (Mitovasc project), by the Foundation for Medical Research (FRM - DPC20171138957) and by GRRC (Groupe de Réflexion sur la Recherche Cardiovasculaire, France)

\begin{abstract}
Hypertension is associated with excessive reactive oxygen species (ROS) production in vascular cells. Mitochondria undergo fusion and fission, a process playing a role in mitochondrial function. OPA1 is essential for mitochondrial fusion. Loss of OPA1 is associated with ROS production and cell dysfunction. We hypothesized that mitochondria fusion could reduce oxidative stress that defect in fusion would exacerbate hypertension. Using (a) Opal haploinsufficiency in isolated resistance arteries from $\mathrm{Opal}^{+/-}$mice, (b) primary vascular cells from $\mathrm{Opal}^{+/-}$mice, and (c) RNA interference experiments with siRNA against $O p a l$ in vascular cells, we investigated the role of mitochondria fusion in hypertension. In hypertension, Opal haploinsufficiency induced altered mitochondrial cristae structure both in vascular smooth muscle and endothelial cells but did not modify protein level of long and short forms of OPA1. In addition, we demonstrated an increase of mitochondrial ROS production, associated with a decrease of superoxide dismutase 1 protein expression. We also observed an increase of apoptosis in vascular cells and a decreased VSMCs proliferation. Blood pressure, vascular contractility, as well as endothelium-dependent and -independent relaxation were similar in $\mathrm{Opal}^{+/-}$, WT, L-NAME-treated $\mathrm{Opal}^{+/-}$ and WT mice. Nevertheless, chronic NO-synthase inhibition with L-NAME induced a greater hypertension in $\mathrm{Opal}^{+/-}$than in WT mice without compensatory arterial wall hypertrophy. This was associated with a stronger reduction in endotheliumdependent relaxation due to excessive ROS production. Our results highlight the protective role of mitochondria fusion in the vasculature during hypertension by limiting mitochondria ROS production.
\end{abstract}

\footnotetext{
Abbreviations: AngII, angiotensin II; DHE, dihydroethidium; DMEM, Dulbecco's Modified Eagle Medium; DOCA, deoxycorticosterone acetate; Drp1, dynamin-related protein; Fis1, mitochondrial fission 1 protein; L-NAME, L- $\mathrm{N}^{\mathrm{G}}$-nitroarginine methyl ester; MA, mesenteric arteries; Mfn1, mitofusin 1; Mfn2, mitofusin 2; Opa1, optic atrophy 1; PSS, physiological salt solution; ROS, reactive oxygen species; SHR, spontaneously hypertensive rat.
}

Pauline Robert and Phuc Minh Chau Nguyen are contributed equally to the study. 


\section{K E Y W O R D S}

hypertension, mitochondria, Opa1, oxidative stress, vascular function

\section{$1 \mid$ INTRODUCTION}

Hypertension is a main risk factor for cardiovascular disorders. Increased vascular oxidative stress has been shown to play a major role in the pathophysiology of hypertension leading to vascular inflammation, and endothelial and smooth muscle cells dysfunction. ${ }^{1}$ Mitochondrial dysfunction could precede endothelial dysfunction and might promote the development of hypertension. Energy requirements in the endothelium are relatively low (mitochondria represent 2\%-6\% of the endothelial cell (ECs) volume compared to $32 \%$ in cardiomyocytes) and glycolysis is the major source of ATP production. It is recognized that endothelial mitochondria play a prominent role in cellular responses through the production of reactive oxygen species (ROS) to signal a change in endothelial phenotype. ${ }^{2}$ The cellular distribution of mitochondria is important for its function and its communication with other cellular organelle (eg, endoplasmic reticulum, ER) and nucleus. In ECs, mitochondria release ROS in response to cell deformation by shear stress. ${ }^{3}$ But oxidative stress could also be induced by an imbalance in cellular calcium hemostasis due to poor cooperation between mitochondria and ER. ${ }^{4}$ Thus, altered mitochondrial calcium contributes to endothelial response to pathological stimuli. Elevated global $\mathrm{Ca} 2+$ concentration in endothelial cells promotes endothelial nitric oxide synthase (eNOS) activation, and consequently nitric oxide (NO) production. ${ }^{5}$

Fusion and fission are essential processes for preservation of normal mitochondrial function. In mammalian cells, mitochondrial fission is controlled by FIS1 and DRP1 while mitochondrial fusion requires the mitofusins MFN1 and MFN2 for the outer membrane fusion, and OPA1 for the inner membrane fusion. These morphological changes are regulated also by proteolytic processing of OPA1 by the innermembrane peptidases YME1L (also known as YME1L1) and OMA1. Long, membrane-bound forms of OPA1 are required for mitochondrial fusion, but their processing to short, soluble forms limits fusion and can facilitate mitochondrial fission. ${ }^{6}$ Besides its role in mitochondrial fusion, OPA1 is also responsible for the maintenance of cristae structure. ${ }^{7}$ Loss of OPA1 leads to mitochondrial fragmentation and disorganization of cristae, subsequently resulting in alterations in mitochondrial function including ATP production by oxidative phosphorylation, calcium homeostasis, and regulation of cell growth and apoptosis. ${ }^{8-12}$ These alterations lead to excessive ROS production as shown in previous studies which have demonstrated that Opal mutations caused the accumulation of oxidative damages in drosophilia (aging and lifespan), ${ }^{11}$ in human lymphoblastoid cell lines from four autosomal dominant optic atrophy families ${ }^{13}$ and in eye-specific somatic mutation ${ }^{14}$ nevertheless no study has shown such a role in vascular cells.

The need for blood vessels to adapt to hypertension increases the energy demand of the vascular smooth muscle cells (VSMCs) and could induce mitochondrial biogenesis and activation of fusion-fission cycles in order to optimize mitochondria functions. Mitochondria are also an important source of cellular ROS production for hypertrophy and cell migration ${ }^{15}$ but the possible protective role of mitochondrial dynamics remains incompletely understood. Clinical investigations have observed a significant increase in OPA1 mRNA and protein expression in the placenta of patients with preeclampsia. ${ }^{16}$ Moreover, genetic variation of $\mathrm{Opal}$ is associated with hypertension in the Korean population suggesting a possible role of mitochondrial fusion in the pathogenesis of hypertension. ${ }^{17}$ Finally, in specific ocular hypertension, mitochondrial OPA1 provides protection against pressuremediated retinal damage ${ }^{18}$ although no systemic hypertension occurs in this pathology. Experimental studies also give unclear results. Indeed, in spontaneously hypertensive rats, mitochondrial dynamics were in favor of fusion ${ }^{19}$; in this model, Tang et al demonstrated a decreased level of mitochondrial fission protein DRP1 while that of OPA1 protein is increased in cardiomyocytes, suggesting a possible role of mitochondrial dynamic in heart damages induced by high blood pressure. ${ }^{20}$ But another study using phenylephrineinduced hypertrophy demonstrated a decrease in mRNA levels of the outer membrane fusion proteins MFN1/MFN2 and OPA1 in the heart of hypertensive rats, suggesting a shift towards increased mitochondrial fragmentation during hypertension. ${ }^{21}$ In the heart, excessive fission has been associated with more ischemia/reperfusion (I/R) injury and cell apoptosis. ${ }^{22}$ Similarly, Le Page et al have demonstrated that Opal deficiency is associated with increased sensitivity to $\mathrm{I} / \mathrm{R}$, imbalance in mitochondrial $\mathrm{Ca}^{2+}$ uptake, and subsequently to an increase in sodium-calcium exchanger activity. ${ }^{23}$

Although OPA1 has been abundantly linked to cardiovascular pathophysiology, to our knowledge its contribution in the pathophysiological mechanisms of arterial hypertension has never been clearly demonstrated. Therefore, we hypothesized that mitochondrial fusion and specifically the long and short forms of OPA1 might contribute to the regulation of vascular function, especially in endothelium-mediated tone which is very sensitive to oxidative stress. We tested this hypothesis on vascular tone and adaptation to high blood 
pressure, challenging an $\mathrm{Opal}^{+/-}$mouse model with LNAME-induced hypertension.

\section{MATERIALS AND METHODS}

\subsection{Animals}

We used a male mouse model carrying the recurrent Opa1c.2708 delTTAG mutation. ${ }^{24} \mathrm{~A}$ total of $93 \mathrm{Opal}^{+/+}$and $93 \mathrm{Opal}^{+/-}$mice aged 6 months were used for all the study: $35 \mathrm{Opal}^{+/+}$and $35 \mathrm{Opal}^{+/-}$mice treated with L-NAME (Sigma-Aldrich, St. Louis, MO, USA) in the drinking water (300 mg/kg/day) during 14 days as previously shown ${ }^{25}$ and $46 \mathrm{Opal}^{+/+}$and $\mathrm{Opal}^{+/-}$non-treated mice. Systolic blood pressure was measured in conscious mice every day using tail cuff plethysmography (noninvasive automated and computerized Visitech BP2000 Systems Inc). For good quality, reliability, and reproducibility of measurements, mice were previously trained during $7 \mathrm{~d}$ before treatment. After $21 \mathrm{~d}$ of measurement ( $7 \mathrm{~d}$ without treatment and $14 \mathrm{~d}$ with treatment) mice were sacrificed and mesenteric resistance arteries were quickly removed and placed in an ice-cold physiological salt solution (PSS). Different arterial segments (second order of mesenteric arteries) were used for cell culture, pharmacological, biochemical, immuno-histological, and mitochondrial length and cristae analyses as described below.

The experimental procedures followed for the care and euthanasia of animals were in accordance with the European Community Standards on the Care and Use of Laboratory Animals (Ministère de l'Agriculture, France, authorization number 6422). Protocols were approved by the regional ethical committee (Protocol CEEA PdL number CEEA.2012.21).

\section{2 | Primary cell culture}

Vascular Smooth muscle cells were obtained from the whole mesentery arterial bed of WT and $\mathrm{Opal}^{+/-}$mice. First, adventitial peripheral fat was removed. Then, arterial wall was enzymatically digested with elastase $(0.125 \mathrm{U} / \mathrm{mL})$ and collagenase $(2 \mathrm{U} / \mathrm{mL})$ (Worthington, Lakewood NJ, USA) for 3 hours at $37^{\circ} \mathrm{C}$ under agitation in DMEM medium without serum. Vascular smooth muscle cells were maintained in DMEM medium (Lonza, Basle, Switzerland) supplemented with $10 \%$ fetal bovine serum (Biowest, Nuaille, France), glutamine (2 mM, Lonza), penicillin (100 U/mL, Lonza), and streptomycin $\left(100 \mu \mathrm{g} / \mathrm{mL}\right.$, Lonza), and maintained at $37^{\circ} \mathrm{C}$ with 5\% carbon dioxide and 95\% humidity. Cells between P2 and P4 were seeded in Petri dish. Once reached $80 \%$ of confluence, cells were treated with Angiotensin II (AngII $10^{-6} \mathrm{M}$, Sigma-Aldrich) or DMEM medium for 24 hours. Stimulation was stopped with PBS washing, and cells were used for electronic microscopy or western blot analysis. Specificity of primary VSMCs were determined by gene expression of contractile proteins Myh11, Mylk, and Myl9 (SUP8), using real-time qPCR.

\subsection{Transmission electron microscopy}

Primary cells and mesenteric arteries were fixed in glutaraldehyde $2.5 \%$ and $60-\mathrm{nm}$ thick sections were cut with an ultramicrotome, and examined using a JEOL JEM 1400 electron microscope (SCIAM platform, University of Angers). Measurements of mitochondrial cristae width were conducted using the Image J software (NIH, USA).

\subsection{D fluorescence microscopy}

Cells were then incubated for 15 minutes with $100 \mathrm{nM}$ Mitotracker green (Molecular Probes, Sunnyvale, CA, USA) to stain mitochondrial network. For fluorescence imaging, coverslips were mounted in housing and placed on the stage of an inverted wide-field microscope ECLIPSE Ti-E (Nikon, Champigny sur Marne, France) equipped with a 100x oil immersion objective (Nikon Plan Apo100, NA 1.45) and an Andor NEO sCOMS camera controlled by Metamorph 7.7 software (Molecular Devices). A precision, piezoelectric driver mounted underneath the objective lens allowed faster Z-step movements, keeping the sample immobile while shifting the objective lens. Twenty-one 2D images were acquired along the Z-axis at $0.2 \mu \mathrm{m}$ increments. For mitochondrial network characterization, acquired images were iteratively deconvolved using Huygens Essential software (Scientific Volume Imaging, Hilversum, The Netherlands), with a maximum iteration scored 50 and a quality threshold at 0.01 . After this deconvolution step and applying a threshold to separate the mitochondrial signal from the background, Imaris 8.0 software (Bitplane, Zurich, Switzerland) created a 3D mask around the fluorescent signal that we call the 3D model of the mitochondrial network. ${ }^{26,27}$

\section{5 | Histomorphometric analysis}

Mesenteric arterial segments pressurized at $75 \mathrm{~mm} \mathrm{Hg}$ and fixed in $4 \%$ para-formaldehyde solution were cut using a cryostat. Transverse sections $(7 \mu \mathrm{m}$ thick) were stained with an orcein solution. After image acquisition (Olympus T100 microscope, Sony camera), internal and external medial circumferences and media thickness were measured and 
analyzed using the ImageJ software. Using these values, the cross-sectional area (CSA) was calculated as previously described. $^{28}$

\subsection{Pharmacological reactivity of isolated arteries}

Segments of mesenteric resistance arteries (second order, $2 \mathrm{~mm}$ long) were mounted on a $610 \mathrm{M}$ wire-myograph (Danish Myo Technology, Aarhus, Denmark) as previously described. ${ }^{29}$ For each condition, two arterial segments of each mice were used and averaged as a single value. Two tungsten wires ( $40 \mu \mathrm{m}$ diameter) were inserted into the lumen of the arteries and respectively fixed to a force transducer and a micrometer. Arteries were bathed in a physiological salt solution (PSS) of the following composition (mmol/L): 130.0, $\mathrm{NaCl} ; 15.0, \mathrm{NaHCO}_{3} ; 3.7, \mathrm{KCl} ; 1.6, \mathrm{CaCl}_{2} ; 1.2, \mathrm{MgSO}_{4}$, and 11.0, glucose ( $\left.\mathrm{pH} 7.4,37^{\circ} \mathrm{C}\right)$. Wall tension was applied as previously described. ${ }^{30}$ After a 45 -min equilibration period under applied wall tension, artery viability was tested using a potassium rich PSS $(80 \mathrm{mmol} / \mathrm{L})$. Then, cumulative concentration-response curve to phenylephrine $(1 \mathrm{nmol} / \mathrm{L}$ to $10 \mu \mathrm{mol} / \mathrm{L}$ ) was performed. After washout, the arteries were pre-contracted with phenylephrine to a level approximately equivalent to $50 \%$ of the maximal response. Cumulative concentration-response curves to acetylcholine $(1 \mathrm{nmol} / \mathrm{L}$ to $10 \mu \mathrm{mol} / \mathrm{L})$ were done. ${ }^{31}$ On the second artery, after viability test, the arteries were precontracted with phenylephrine $(10 \mu \mathrm{mol} / \mathrm{L})$. In order to test the NO sensitivity of the VSMCs, a cumulative concentration-response curve to a NO donor, sodium nitroprusside (SNP) ( $1 \mathrm{nmol} / \mathrm{L}$ to $3 \mu \mathrm{mol} / \mathrm{L})$ was performed.

\section{7 | Detection of reactive oxygen species using confocal microscopy in resistance arteries}

Frozen mesenteric arterial segments were cut using a cryostat to obtain transverse sections of $7 \mu \mathrm{m}$ thick. Dihydroethidium microphotography (DHE; Sigma-Aldrich) was used to evaluate superoxide production in arteries, as previously described. ${ }^{28}$ Cells are permeable to DHE, which is oxidized by superoxide to form fluorescent products, which are, in turn, trapped by intercalation in the DNA. Sections were incubated with $1 \mathrm{mmol} / \mathrm{L}$ of $\mathrm{DHE}$ at $37^{\circ} \mathrm{C}$ for 30 minutes in a humidified chamber protected from light. Fluorescent images of DHE were obtained by using confocal microscopy and the QEDimage software (Solamere Technology, Salt Lake City, UT, USA). Pixel quantification was executed as also described previously. ${ }^{28}$ A positive control was performed using a section of mesenteric artery treated for 2 hours with lipopolysaccharide in vitro at $37^{\circ} \mathrm{C}$ in a physiological salt solution
(100 of Arbitrary unit). A negative control was obtained by omitting DHE or by adding Tempol to the section 15 minutes before DHE (0 of Arbitrary unit).

\subsection{Quantitative real-time PCR}

Mesenteric arteries were dissected in ice cold PBS and stored at $-20^{\circ} \mathrm{C}$ in RNAlater Tissue Storage Reagent (Sigma-Aldrich). RNA extraction was performed using the RNeasy micro kit (Qiagen, Hilden, Germany). A quantity of $100 \mathrm{ng}$ of total RNA were subjected to reverse transcription with the QuantiTect Reverse Transcription kit (Qiagen). Real-time PCR was performed with Sybr Green PCR master mix (Applied Biosystems, Foster, CA, USA) on using a LightCycler 480 Real-Time PCR System (Roche, Branchburg, NJ, USA). 7500 SDS Real-Time PCR system (Applied Biosystems). Relative expression was calculated

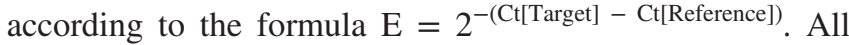
data were normalized to the Gusb, Hprt and Gapdh mRNA Gapdh, Hprt and Gusb were used as housekeeping genes. Analysis was not performed when $\mathrm{Ct}$ values exceeded 35 . Results were expressed as: $2(\mathrm{Ct}$ target- $\mathrm{Ct}$ housekeeping gene).

\section{9 | Western blot analysis}

Western blots were performed on VSMCs primary culture from mesenteric arteries and whole on mesenteric arteries tissues. Mesenteric arteries from WT and $\mathrm{Opal}^{+/-}$mice with or without L-NAME treatment were crushed and extracted in SDS lysis buffer (SDS 20\%, Tris 500 mM pH7.4, halt protease \& phosphatase inhibitor cocktail, 0.5 M EDTA solution). VSMCs were directly extracted in SDS lysis buffer. The homogenate of mesenteric arteries and cells in lysis buffer was centrifuged at $13000 \mathrm{rpm}$ at $4^{\circ} \mathrm{C}$ for 20 minutes, and the supernatant was then collected. Protein concentration was determined using Micro BCA protein assay kit (Thermo Fisher Scientific, Waltham, MA, USA) according to the manufacturer's instructions. After solubilization in $25 \mu \mathrm{L}$ of Laemmli sample buffer containing 5\% $\beta$-mercaptoethanol, boiled 5 minutes at $90^{\circ} \mathrm{C}$, equal amounts of proteins $(10 \mu \mathrm{g})$ were separated on 4\%-15\% polyacrylamide gel electrophoresis (BioRad, Marnes la Coquette, France) and transferred to a nitrocellulose membrane (BioRad). For OXPHOS protein detection, $10 \mu \mathrm{g}$ were solubilized in $25 \mu \mathrm{L}$ of Laemmli sample buffer containing $5 \%$ $\beta$-mercapto ethanol, boiled 5 minutes at $45^{\circ} \mathrm{C}$ and separated by $12 \%$ polyacrylamide gel electrophoresis (Bio-Rad) and transferred to a PVDF membrane (Bio-Rad). Proteins were detected with specific antibodies: Total Oxphos cocktail (1:500, Abcam, Cambridge, UK), NDUFS1 (1:2000, Abcam), OPA1 (1:1000 BD Biosciences, Le Pont de Claix, France), Collagen I 
(1:250, Abcam), Collagen III (1:1000, Abcam), Elastin (1:500, Abcam), SOD 1 (1:1000, EnzoLife Sciences, Villeurbanne, France), SOD 2 (1:1000, EnzoLife Sciences), iNOS (1:1000, BD Biosciences), VDAC (1:1000, Abcam), GAPDH (1:2000, Cell Signaling Technology). The amount of targeted proteins was normalized to the total protein amount (Ponceau staining) present in each line.

\subsection{0 | RNA interference}

Vascular smooth muscle cells from MOVAS (American Type Culture Collection ATCC) were maintained in DMEM medium (Lonza), supplemented with $10 \%$ fetal bovine serum and $200 \mu \mathrm{g} /$ mL G-418 (Sigma). Vascular endothelial cells from MS1 (American Type Culture Collection ATCC, MILE SVEN1) were maintained in DMEM medium (Lonza), supplemented with $5 \%$ fetal bovine serum. Cells were maintained at $37^{\circ} \mathrm{C}$ in $5 \%$ carbon dioxide. RNA interference experiments were performed by transfection of $50 \mathrm{nM}$ of a control and a prevalidated siRNA against Opal (Ambion ID AS010402), using the Lipofectamine RNAiMAX (Thermo Fisher), according the manufacturer's instructions, and followed by a $48 \mathrm{~h}$ incubation.

To verify siRNA efficiency, Western blot assay of OPA1 was carried out. Transfected cells were trypsinized, washed once in ice-cold PBS, and harvested. Equal amounts of cells were solubilized in $25 \mu \mathrm{L}$ of Laemmli sample buffer were separated by SDS-PAGE using a $4 \%$ stacking gel followed by a $10 \%$ running gel. Proteins were detected with specific antibodies: OPA1 (1:1000, BD Biosciences), beta-actin (1:5000, Sigma-Aldrich), and a second antibody anti-mouse HRP (1:5000, Thermofisher). After 48 hours of transfection, cells were incubated with Angiotensin II $\left(10^{-6} \mathrm{M}\right)$ for 24 hours, then proliferation assay or apoptosis assay or mitochondrial superoxide assay were conducted.

\subsection{Mitochondrial superoxide assay}

Cells grown on glass coverslips were incubated with Mitotracker Green FM (200 nM, Thermo Fisher Scientific) and Mitosox Red ( $5 \mu \mathrm{M}$, Thermo Fisher Scientific) following the manufacturer's instructions. The percentage of positive cells was calculated using the Image J software.

\subsection{Apoptosis assay}

Cells grown on glass coverslips were fixed in paraformaldehyde $4 \%$. Blocking of unspecific protein binding sites was carried out in PBS-BSA 5\%. Cells were incubated with primary antibody Cleaved Caspase-3 (1:100, Merck Millipore, France) overnight at $4{ }^{\circ} \mathrm{C}$. Then, cells were incubated with secondary antibody Anti-Rabbit IgG PE (1:100, Thermo Fisher Scientific) and DAPI (1:1000, Sigma-Aldrich) for 2 hours at room temperature in the dark. Percentage of cleaved caspase-3-positive cells per total cells was assessed.

\subsection{Proliferation assay}

Ki67 immuno-histochemical labeling was performed and cells grown on glass coverslips, according to manufacturer's instructions. For that purpose, 7- $\mu$ m-thick frozen sections of aorta were prepared, fixed in paraformaldehyde 4\%. After blocking unspecific protein binding sites in PBS-BSA 5\%, the sections were incubated with fluorescent conjugated antibody antiKi67-eFluor 570 (1:100, Thermo Fisher Scientific) and DAPI (1:1000, Sigma- Aldrich) for 2 hours at room temperature in the dark. Then, glass coverslips were observed with a confocal microscope. The percentage of Ki67 positive cells was calculated.

\subsection{Statistical analysis}

Results were expressed as means \pm SEM. Statistical analysis was performed using GraphPad Prism software (San Diego, CA, USA). For vascular reactivity, a two-way ANOVA for consecutive measurements was used followed by a Bonferroni's post-test. A Mann-Whitney test was used for all other results. All results were considered as significantly different when $P<.05$.

\section{3 | RESULTS}

\section{1 | Impact of OPA1 on mitochondrial length and cristae morphology in primary VSMCs and whole mesenteric arteries}

To test if OPA1 influenced mitochondrial length and cristae morphology in vascular cells in normal or hypertensive condition, transmission electron microscopic observations were performed both on primary VSMCs of mesenteric arteries and on whole resistance arteries (Figure 1).

Opal haploinsufficiency reduced mitochondria length in primary VSMCs and whole mesenteric arteries in both normal and hypertensive condition (Figure 1B,E). Furthermore, a mitochondrial fragmentation and disorganized cristae were found in primary VSMCs but neither in whole mesenteric arteries nor in hypertensive condition (Figure 1C,F). In the same way, the Opal siRNA (siOpac1) induced reduction of the mitochondria length in the VSMCs, a mitochondrial fragmentation, with less disorganized cristae, unusual shapes (ie, vesicle-like structures). In parallel, siOpa1 ECs showed enlarged cristae (Figure S1A,B). 
(A)

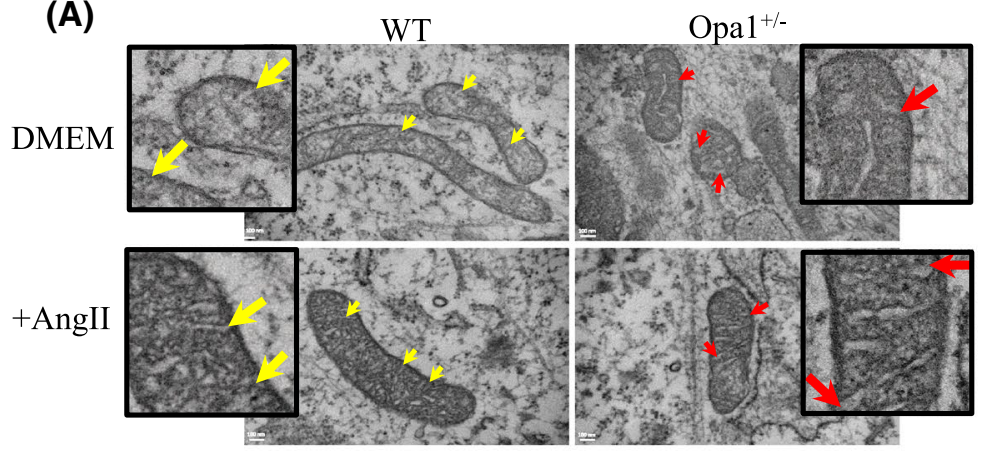

(B) VSMCs (MA primary culture)

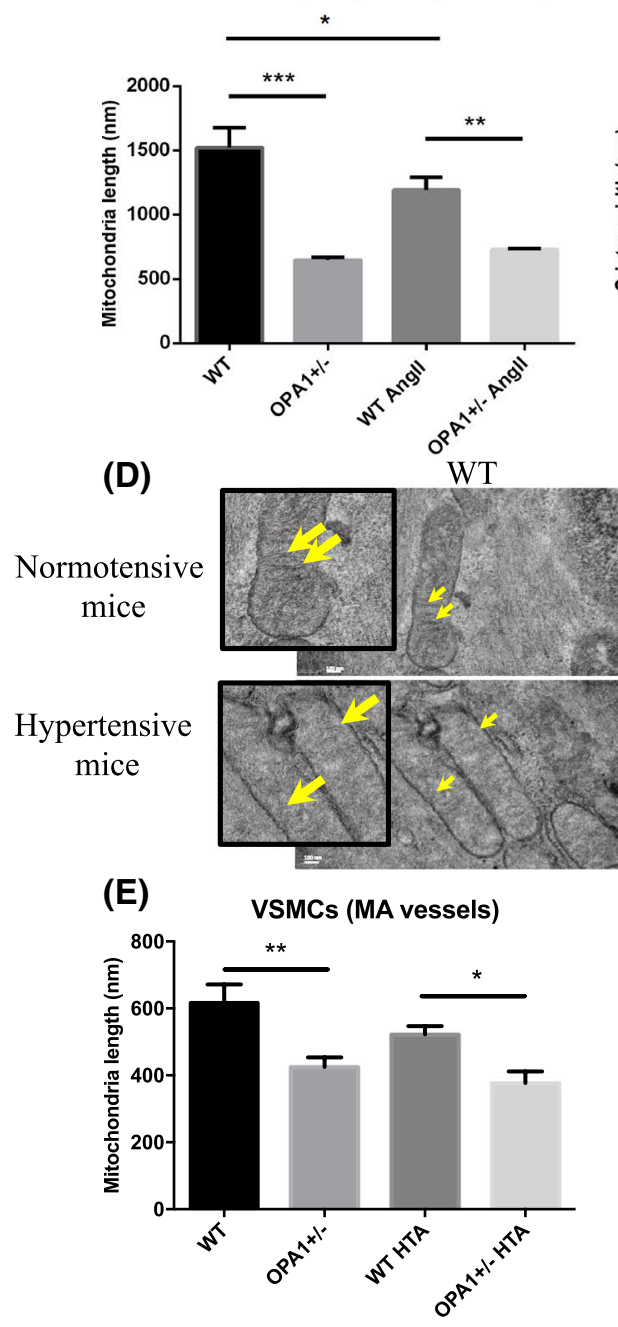

\section{2 | Impact of OPA1 on}

mitochondrial fragmentation in primary VSMCs of mesenteric arteries in normal and hypertensive conditions

In order to characterize the impact of OPA1 on mitochondrial network architecture, mitochondrial morphology was investigated in primary VSMCs isolated from mesenteric arteries of WT and $\mathrm{Opal}^{+/-}$mice in the presence or absence of AngII.

Representative images of the mitochondria in VSMCs are shown in Figure 2A. Four phenotypes of mitochondrial shape

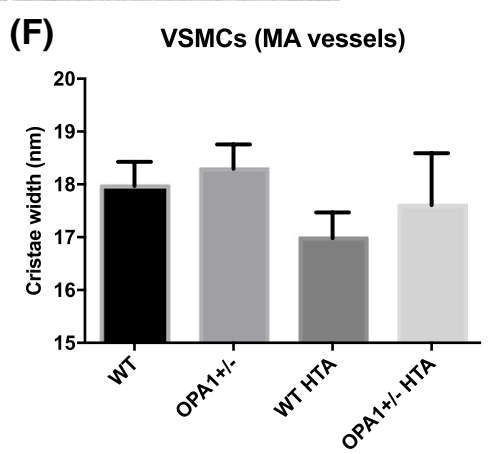

F I G URE 1 Mitochondrial length and cristae morphology in primary VSMCs treated with AngII $\left(10^{-6} \mathrm{M}\right.$ or DMEM, $24 \mathrm{~h}, \mathrm{~A}, \mathrm{~B}, \mathrm{C})$ and in whole mesenteric arteries from normotensive or hypertensive mice treated with L-NAME in the drinking water $(5 \mathrm{mg} / 10 \mathrm{~mL}, 14 \mathrm{~d}, \mathrm{D}, \mathrm{E}, \mathrm{F})$ ( $\mathrm{n}=30-50$ mitochondria used for analysis in each animal. Red Arrows correspond to disorganized cristae, Yellow Arrows correspond to normal cristae. Mean \pm SEM is shown ( $\mathrm{n}=5$ mice per group), ${ }^{*} P<.05$, $* * * P<.001$ 

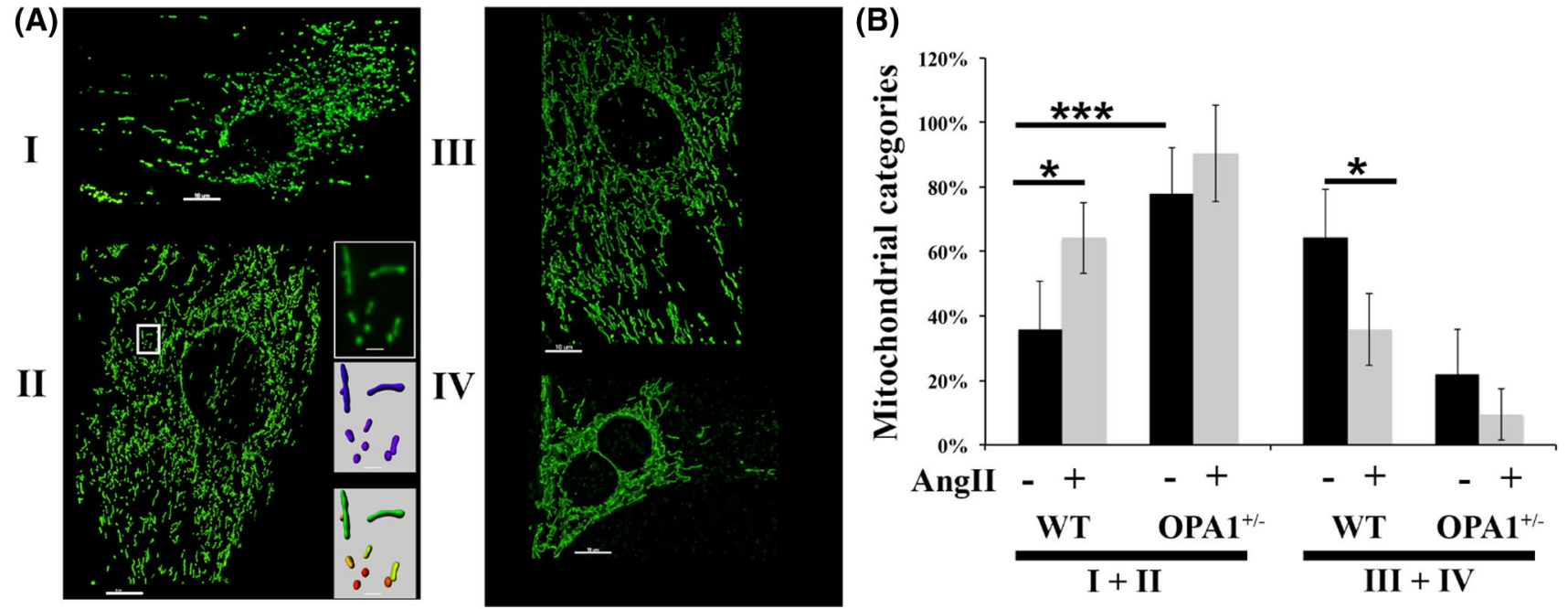

F I G URE 2 AngII promotes mitochondrial hyperfragmentation in VSMCs. A, VSMCs were loaded with MitoTracker Green probes as described in Section 2. Mitochondrial shape and distribution of WT and Opa ${ }^{+/-}$VMSCs were classified in four categories (I-IV) and representative images are shown. Details show enlargement of some mitochondria; the mitochondrial shape were assessed and color-coded. B, Histograms indicate the proportion of WT and OPA $1^{+/-}$VSMCs within subcategories (I+II) and (III+IV). Values are the mean \pm SEM of at least 60 measurements from two independent acquisitions for each animal. Scale bar $=10 \mu \mathrm{m}$. Statistical analysis was carried out using non-parametric Mann-Whitney test, $* * * P$-value $<0.001, \mathrm{n}=8$ mice per group

Moreover, in these isolated mitochondria, a high proportion of rounded shape was found (Figure 2B II + I). The histograms show the distribution of the mitochondrial population in 4 different categories on the basis of mitochondrial volume. Following AngII treatment, the mitochondrial interconnected network of WT VSMCs became hyper-fragmentated with an increase rate of short mitochondria $0.1 \mu \mathrm{m}^{3}$.

\section{3 | Impact of OPA1 on L-NAME-induced hypertension}

In vivo studies were realized in order to investigate the impact of OPA1 in hypertension. We observed no significant

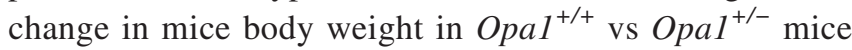
in normal $(32.0 \pm 1.2 \mathrm{~g} ; \mathrm{n}=11$ vs $31.0 \pm 1.3 \mathrm{~g} ; \mathrm{n}=10)$ or hypertensive $(30.0 \pm 0.4 \mathrm{~g} ; \mathrm{n}=7$ vs $29.0 \pm 0.9 \mathrm{~g}$; $\mathrm{n}=9$ ) conditions. Systolic blood pressure (SBP) was not significantly different in $\mathrm{Opal}^{+-}$mice than in WT mice $\left(121 \pm 1 \mathrm{~mm} \mathrm{Hg}\right.$ in $\mathrm{Opal}^{+/-}$mice vs $119 \pm 1 \mathrm{~mm} \mathrm{Hg}$ in WT mice before treatment, Figure 3A, Day 0). Furthermore, to evaluate whether partial depletion of OPA1 affect vascular function in stress condition, we treated WT and $\mathrm{Opal}^{+/-}$mice by L-NAME to induce hypertension. After $6 \mathrm{~d}$, SBP was higher in $\mathrm{Opal}^{+/-}$mice than in WT mice. Fourteen days after L-NAME treatment, SBP was significantly greater in $\mathrm{Opal}^{+/-}$mice than in WT mice $(150 \pm$ $1 \mathrm{~mm} \mathrm{Hg}$ in $\mathrm{Opal}^{+/-}$mice vs $140 \pm 2 \mathrm{~mm} \mathrm{Hg}$ in WT mice) (Figure 3A). Mesenteric arteries of L-NAME-treated $\mathrm{Opal}^{+/-}$and WT mice displayed a similar increase in the media/lumen ratio compared to mesenteric arteries of non-treated mice (Figure 3B), suggesting that no further hypertrophy occurred in hypertensive $\mathrm{Opal}^{+/-}$mice despite higher hypertension as compared to WT mice.

\section{4 | Vascular reactivity of mesenteric arteries in $\mathrm{OpaI}^{+/-}$hypertensive mice}

Phenylephrine-mediated contraction of mesenteric arteries was not different between WT and $\mathrm{Opal}^{+/-}$mice without or with L-NAME treatment (Figure 4A,B). In addition, no significant difference in endothelium-dependent relaxation induced by acetylcholine was observed between WT and $\mathrm{Opal}^{+/-}$mice (Figure 4C). But, acetylcholine-mediated endothelium-dependent relaxation of mesenteric arteries was lower in L-NAME-treated WT and $\mathrm{Opal}^{+/-}$mice than in non-treated mice; thus L-NAME treatment induced endothelial dysfunction. The reduction in acetylcholinemediated relaxation was significantly higher in L-NAMEtreated $\mathrm{Opal}^{+/-}$mice than in L-NAME-treated WT mice (Figure 4D). Finally, no significant difference was observed between the two groups of mice in endothelium-independent relaxation to the SNP in mesenteric arteries (Figure 4E) and in L-NAME-treated WT and $\mathrm{Opal}^{+/-}$mice (Figure 4F).

\section{5 | Impact of OPA1 on oxidative stress in whole mesenteric arteries}

ROS level was higher in mesenteric arteries of hypertensive mice compared to normotensive mice in both 
(A)

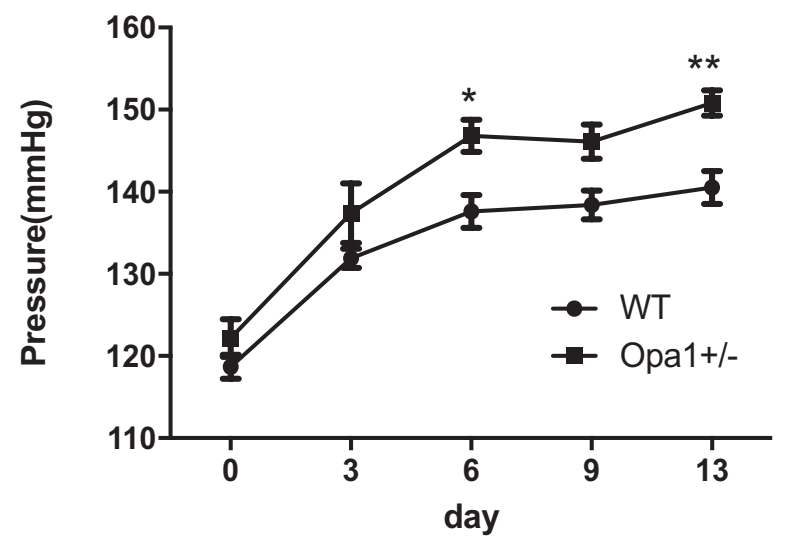

(B)

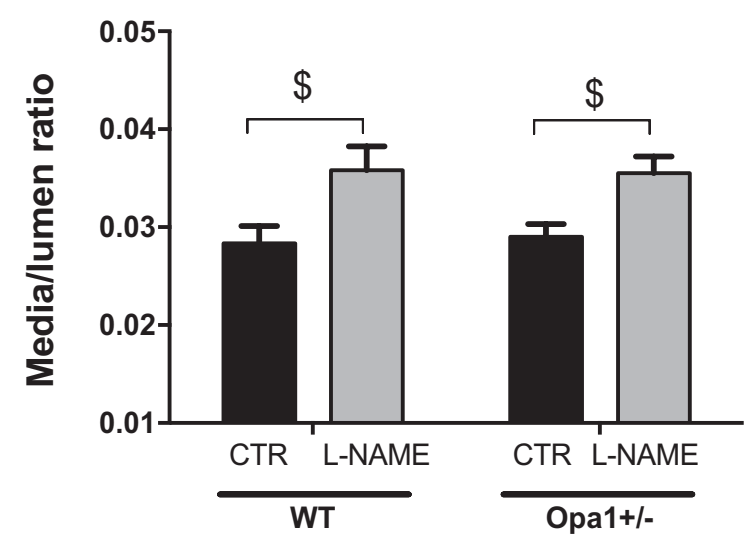

F IG U RE 3 L-NAME-mediated hypertension in WT and $\mathrm{Opal}^{+/-}$ mice (A). $\left({ }^{*} P<.05,{ }^{*} P<<.01, \mathrm{Opal}^{+/-}\right.$hypertensive mice versus WT hypertensive mice) ( $\mathrm{n}=10$ mice per group). Media/lumen ratio of mesenteric arteries (B) in WT and $\mathrm{Opal}^{+/}$, WT hypertensive (WT LNAME) and $\mathrm{Opal}^{+/-}$hypertensive mice $\left(\mathrm{Opal}^{+/-} \mathrm{L}-\mathrm{NAME}\right),(\mathrm{n}=5-7$ mice per group), $\left({ }^{\$} P<.05\right.$, hypertensive versus normotensive mice)

$\mathrm{Opal}^{+/-}$and WT mice (Figure 5A). The mesenteric arteries of $\mathrm{Opal}^{+/-}$hypertensive mice displayed a significantly higher ROS level than in WT hypertensive mice (Figure 5A).

We then evaluated gene expression level of antioxidant enzymes including Sod1, Sod2 and Gpxl in the different groups of mice. Expression of Sodl in $\mathrm{Opal}^{+/-}$mice and LNAME-treated $\mathrm{Opal}^{+/-}$mice were significantly lower than in WT mice and L-NAME-treated WT mice (Figure 5B1). In addition, Sod2 expression was significantly lower in LNAME-treated $\mathrm{Opal}^{+/-}$mice in comparison with $\mathrm{Opal}^{+/-}$ mice while it was not different between the two groups of WT mice (Figure 5C1). The protein levels of SOD1 and SOD2 were also altered. SOD1 protein levels were significantly lower in $\mathrm{Opal}^{+/-}$treated mice than in WT treated mice (Figure 5B2). SOD2 protein level were significantly higher in
$\mathrm{Opal}^{+/-}$treated mice than in WT treated mice (Figure 5C2). Besides, the expression level of GPX1 was comparable between these groups of mice (Figure 6A). Similarly, eNOS gene expression level was not different between WT mice and $\mathrm{Opal}^{+/-}$mice (Figure 6B).

\subsection{Impacts of Opa1 silencing on mitochondrial superoxide generation}

Impact of Opal silencing on vascular cells was then investigated. Opal deletion has been reported to increase mitochondrial ROS (mROS) generation. ${ }^{11,13}$ Therefore, mitochondrial superoxide was evaluated in VSMCs transfected with Opal siRNA. Compared to siCTR, the production of mitochondrial ROS in siOpa1 VSMCs was not different in normal condition, but was significantly increased after treatment by AngII $10^{-6} \mathrm{M}$ for 24 hours (Figure S2A). In ECs, siRNA mediated Opal silencing potentiated the mROS generation induced by AngII (Figure S2B).

\subsection{Impacts of Opal silencing on vascular cells apoptosis and proliferation}

The role of OPA1 in apoptosis of vascular cells was then tested. Opal silencing did not increase spontaneous apoptosis in VSMCs. However, AngII increased the cleaved caspase 3 positive cells in siOpa1 VSMCs, but not in those transfected with siCTR cells. In ECs, loss of OPA1 (siOpa1 ECs) induced apoptosis and AngII had no effect (Figure S3A,B). In addition, AngII induced an increased percentage of ki67 positive cells in VSMCs infected with siCTR and CTR cells, whereas this increase was blunted in siOPA1-treated VSMCs (Figure S4).

\section{8 $\quad$ Mitochondrial gene expression in whole mesenteric arteries}

Finally, we evaluated the expression of mitochondrial transcription factor A (Tfam), which is required for mitochondrial DNA (mtDNA) transcription and replication, and nuclear respiratory factor $1(N r f l)$ which has been shown to regulate expression of many genes involved in mitochondrial function and mitochondrial biogenesis. ${ }^{32,33}$ Gene expression level of Tfam was increased in $\mathrm{Opal}^{+/-}$mice compared to WT mice (Figure 6C). Nrfl gene expression level in LNAME-treated $\mathrm{Opal}^{+/-}$mice was higher than in L-NAMEtreated WT mice (Figure 6C). Mfnl expression level was higher in L-NAME-treated $\mathrm{Opal}^{+/-}$mice and $\mathrm{Opal}^{+/-}$mice in comparison with L-NAME-treated WT mice and WT mice (Figure 6E). However, there was no significant difference in 
FIGURE 4 Vascular reactivity in WT and $\mathrm{Opal}^{+/-}$mice. Concentration-response curves to phenylephrine, acetylcholine, SNP were performed in mesenteric arteries of normotensive mice (A, C, E) and hypertensive mice $(B, D, F)$. Mean \pm SEM is presented ( $\mathrm{n}=5-9$ mice per group). ${ }^{\$} P<.05$, WT versus WT+L-NAME, ${ }^{\$} \mathrm{P}<.05 \mathrm{Opal}^{+/-}$versus $\mathrm{Opal}^{+/-}+\mathrm{L}-$ NAME, $* P<.05$, WT+L-NAME versus $\mathrm{Opal}^{+-}+$L-NAME

\section{Normotensive}

(A)

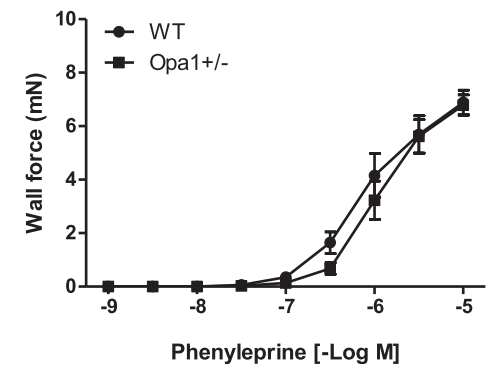

(C)

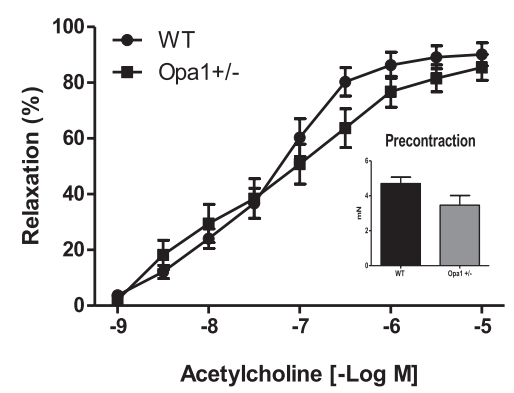

(E)

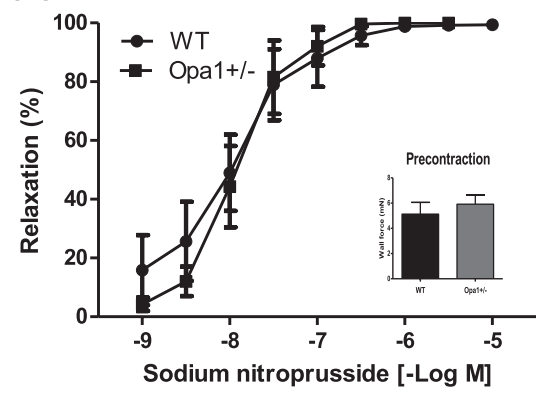

Hypertensive

(B)

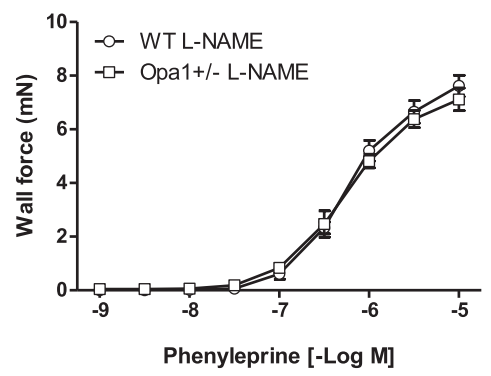

(D)

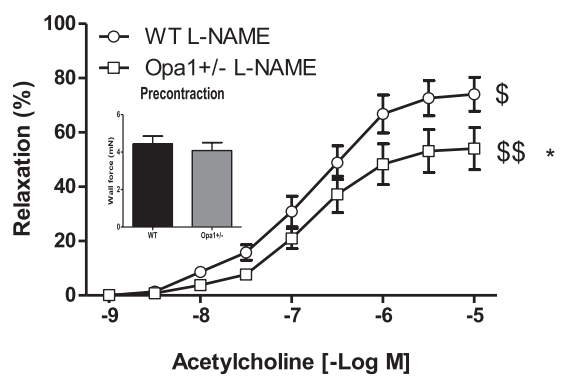

(F)

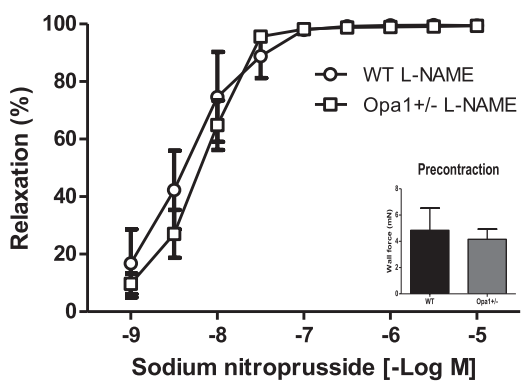

the gene expression level of $M f n 2$ between these groups of mice (Figure 6F).

\section{9 | Mitochondrial Oxidative Phosphorylation (OxPhos) in primary VSMCs and whole mesenteric arteries}

No significant difference was found in the expression of OxPhos proteins in primary VSMCs from mesenteric arteries (Figure 7).

Also, we evaluated the expression of mitochondrial oxidative phosphorylation system in whole mesenteric arteries (Figure 8). We measured the NADPH-ubiquinone oxidoreductase (NDUFS1), Succinate deshydrogenase (CII-SDH8), Cytochrome b-c1 complex subunit 2 (CIII-UQCRC2), Cytochrome c oxidase subunit 1 (CIV-MTCO1), and the ATP Synthase (CV-ATP5A) levels.

Finally, Oxphos western blot complex analysis showed no significant difference in the expression of OxPhos proteins in whole vessel.

\subsection{0 | Mitochondrial OPA1 long (OPA1L) and short (OPA1s) forms in primary VSMCs and whole mesenteric arteries}

No significant difference, with or without hypertension, was found in the expression of total OPA1 protein in primary VSMCs from mesenteric arteries (Figure 9) or in whole mesenteric arteries (Figure 10), but as expected, total OPA1 protein is halved in $\mathrm{Opal}^{+/-}$mice.

Finally, we found similar results for OPA1L or OPA1s form in $\mathrm{Opal}^{+/-}$hypertensive mice compared to $\mathrm{Opal}^{+/-}$ mice in primary VSMCs from mesenteric arteries (Figure 9) or in whole mesenteric arteries (Figure 10).

\section{4 | DISCUSSION}

Studies highlighted the importance of mitochondrial dynamics, in particular the pro-fusion protein OPA1, in cells with high-energy demand such as neurons, skeletal muscle, and 

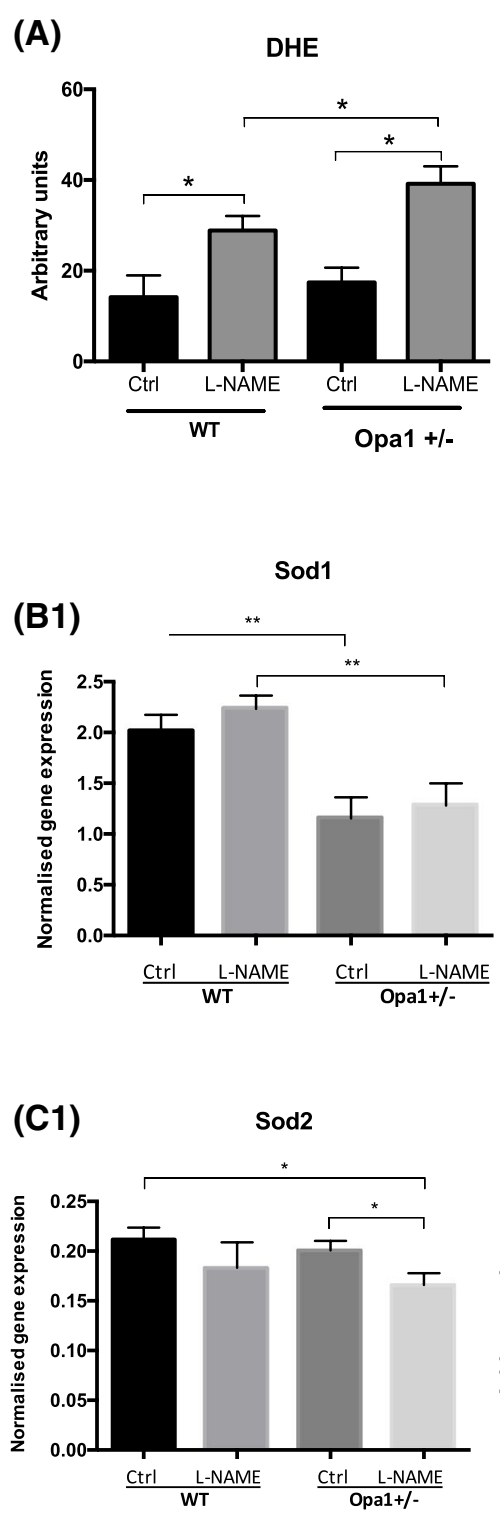
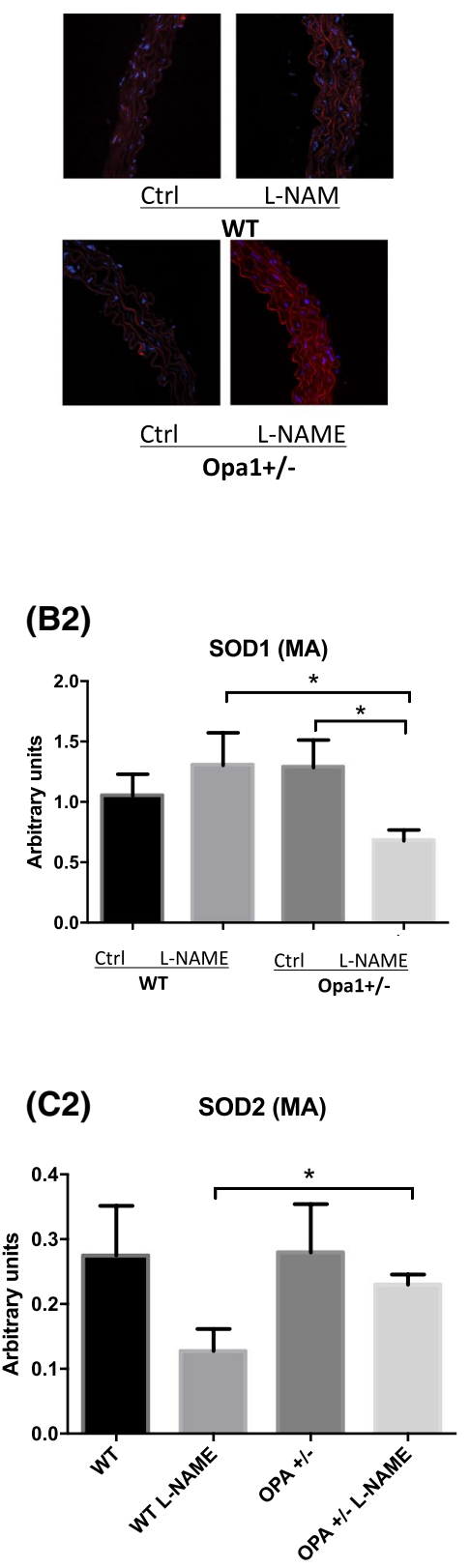

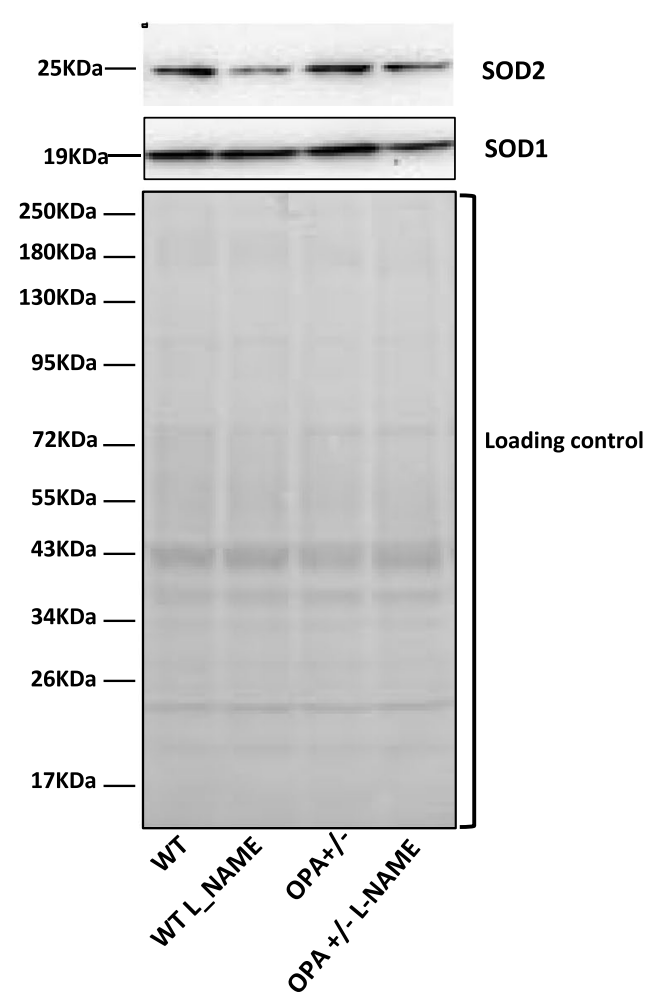

F I G U R E 5 Measurement of ROS level by DHE staining in mesenteric arteries (A) ( $\mathrm{n}=5$ per group); Gene expression level of Sod1 (B) and Sod2 (C) measured using qPCR analysis in mesenteric arteries $(\mathrm{n}=5-8$ mice per group $)\left(* P<.05, \mathrm{Opal}^{+/-}\right.$hypertensive mice versus WT hypertensive mice, ${ }^{\$} P<.05$, hypertensive versus normotensive mice). Western blot examining SOD1 (B2) and SOD2 (C2) protein level in whole mesenteric arteries from normotensive and hypertensive mice, $\left(\mathrm{n}=6\right.$ per group), ${ }^{*} P<.05$, $* * * P<.001$. The amount of targeted proteins was normalized to the total protein amount (Ponceau staining) present in each line

cardiomyocytes. ${ }^{34-36}$ In accordance, our study suggests that mitochondrial fusion has a protective role against hypertension in Opal haploinsufficiency mice model, a total Opal silencing being lethal. Indeed, our results showed, for the first time, impact of decreased mitochondrial fusion on the vasculature during hypertension despite a maintained activity of half of the OPA1 proteins. Although $\mathrm{OpaI}^{+/-}$mice displayed no obvious change in mice body weight, normal blood pressure, and vascular function, they developed a more severe hypertension than $\mathrm{Opal}^{+/+}$mice in association with an altered endothelium-dependent relaxation and excessive oxidative stress of mitochondrial origin. These results were not associated with a difference in iNOS expression after $2 \mathrm{wk}$ of L-NAME treatment. In accordance, Sun et al. described in a model of iNOS knockout mice, that iNOS leads to better preservation of cardiac function induced by a reduced oxidative stress and an increased eNOS without a significant role in preventing hypertension and hypertrophy. ${ }^{37}$

Previous clinical studies showing that, besides abnormalities due to OPA1 protein deficiency get worse visual failure, deafness, peripheral neuropathy, ataxia, and cardiomyopathy but had normal feeding and body weight. ${ }^{24}$ Similarly, 
F I G URE 6 Gene expression level of Gpxl (A), eNOS (B), Nrf1 (C), Tfam (D), $M f n 1$ (E) and $M f n 2(\mathrm{~F})$ measured using qPCR analysis in mesenteric arteries ( $\mathrm{n}=5-8$ per group); $\left({ }^{*} P<.05\right.$, $* * P<.01, \mathrm{Opal}^{+/-}$hypertensive versus WT hypertensive mice)
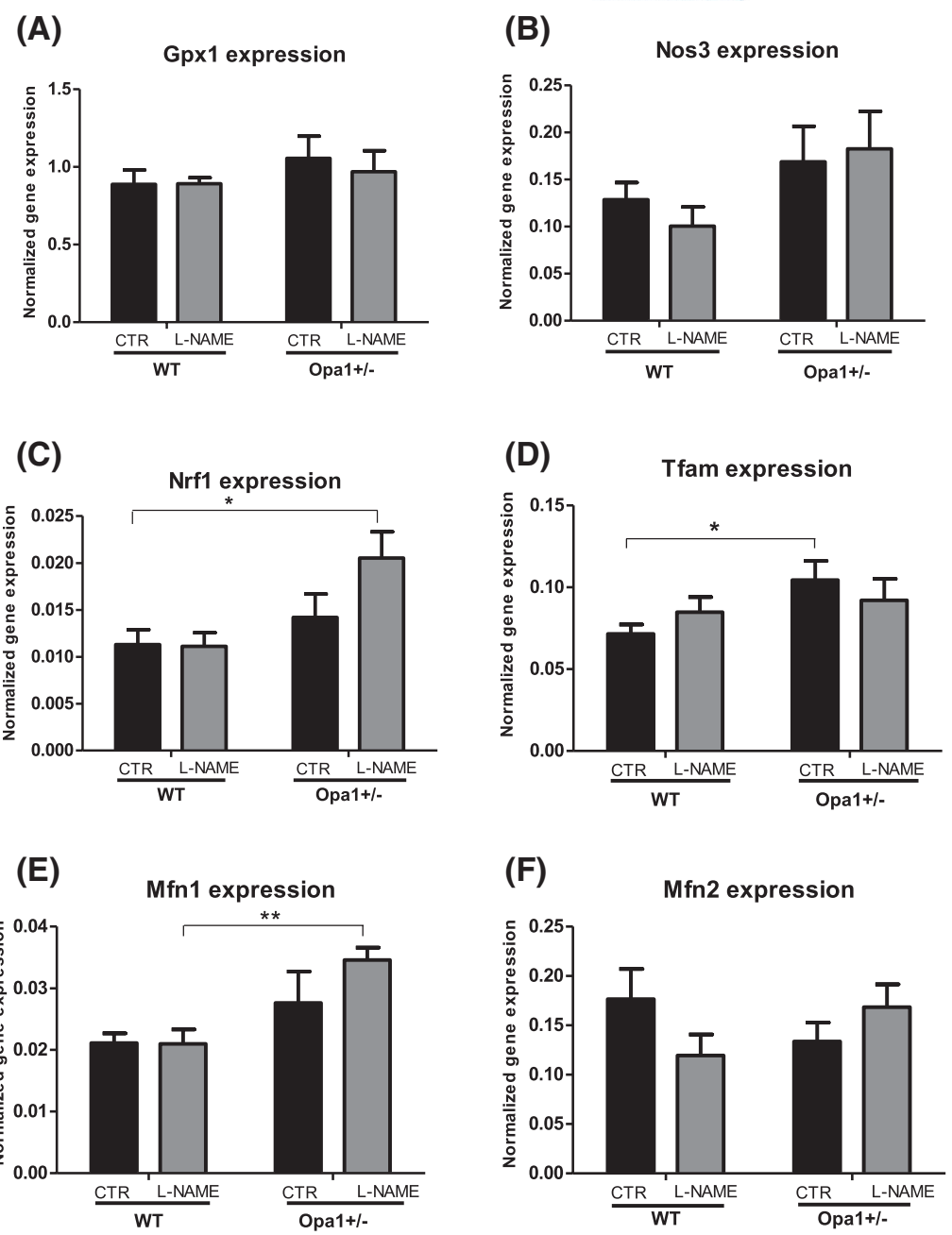

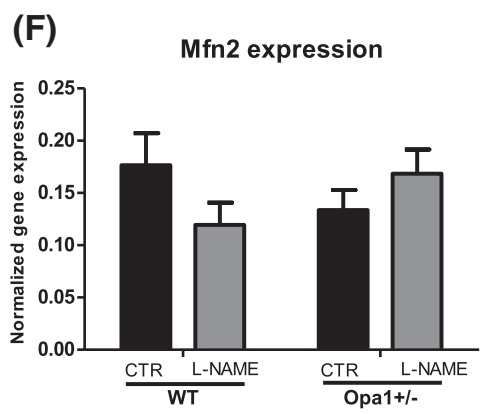

$\mathrm{Opal}^{+/-}$mice body weight was not different from that of $\mathrm{Opal}^{+/+}$mice. $^{23,38}$ Studies have shown that loss of Opal resulted in disruption of cristae structure and increased cell sensitivity to spontaneous and induced apoptosis (supplemental data) ${ }^{7,9}$ Anti-apoptotic function of OPA1 was attributed to the formation of OPA1 oligomers that maintained the structure of the cristae junctions and sequester cytochrome $\mathrm{c}$ within the cristae. ${ }^{7,9,39}$

L-Name treatment induced a lower hypertension compared to angiotensin II infusion with osmotic pump in mice. Because L-NAME-induced hypertension is associated with renin-angiotensin system activation, ${ }^{40}$, we stimulated our cells with Ang II. We observed that Opal haploinsufficiency resulted in altered mitochondria morphology and cristae structure in both primary mouse VSMCs and whole mouse resistance arteries and in Opal silencing MOVAS cells. Opal haploinsufficiency induced mitochondria hyperfragmentation as observed in arteries from hypertensive WT mice. Furthermore, we found that AngII-dependent production of ROS was further increased in Opal-silenced VSMCs compared to control cells, demonstrating that the loss of Opal increased ROS production as it has also been described in diabetes. ${ }^{41,42}$
We found that Opal deficiency in MOVAS VMSCs led to cristae disorganization causing increased cell apoptosis in MS1 ECs and in MOVAS VSMCs after treatment with AngII. This result is in agreement with previous studies performed in invertebrate models bearing Opal mutations and in lymphoblastoid cells of autosomal dominant optic atrophy $(A D O A)$ patients which both present an excessive mROS production associated to mitochondrial dysfunction. ${ }^{11,13,14}$ In mouse embryonic fibroblasts bearing Opal mutations and in fibroblasts from $A D O A$ patients, recent studies have shown an increased percentage of apoptotic cells compared to controls in oxidative stress conditions. ${ }^{7,43}$

Chronic inhibition of NO with L-NAME induced hypertension in both $\mathrm{Opal}^{+/-}$and WT mice. However, Opal haploinsufficiency in $\mathrm{Opal}^{+/-}$mice displayed higher hypertension than WT mice, showing that haplo-insufficiency of Opal had a deleterious impact in a stress condition such as hypertension. This finding suggests a vascular protective effect for Opal under conditions of chronic stress. Our results are consistent with a study showing no evidence of cardiac dysfunction in $\mathrm{Opal}^{+/-}$mice, whereas these mice were more vulnerable to chronic pressure overload. ${ }^{44}$ In agreement with previous studies, ${ }^{45,46}$ we found that L-NAME-induced hypertension 


\section{Oxphos (VSMCs, MA Primary culture)}
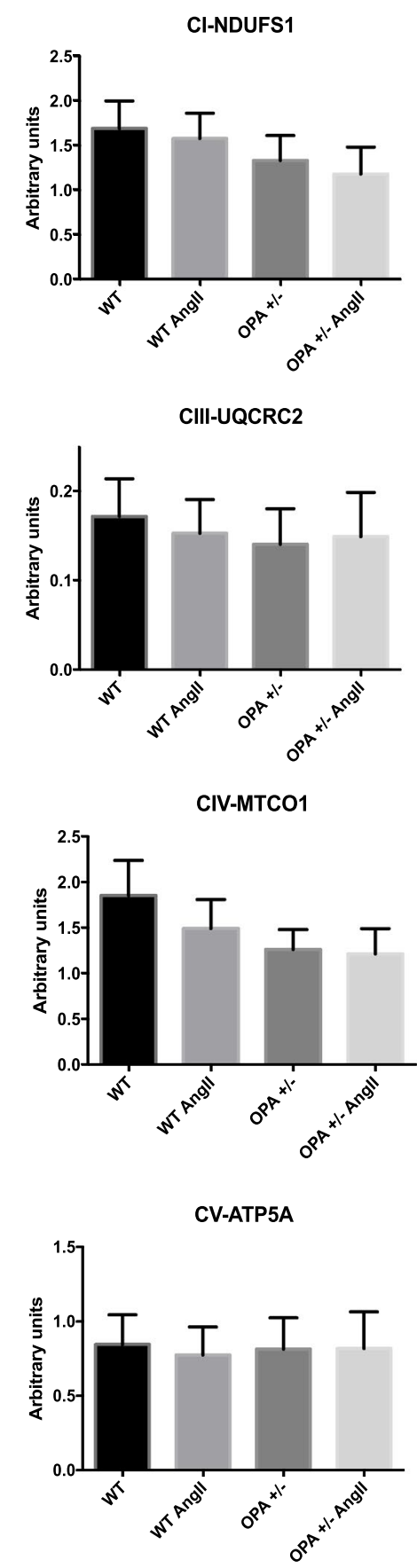
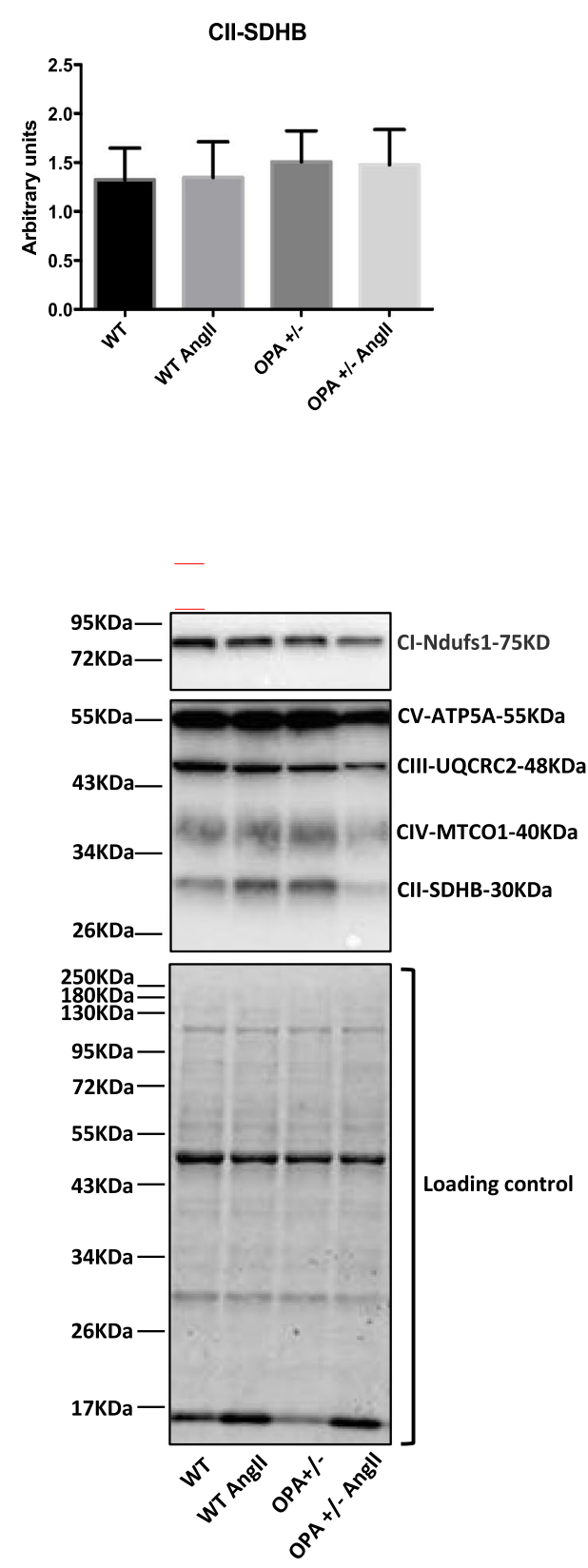

F I G URE 7 Western blot examining Oxphos proteins level in primary VSMCs isolated from mesenteric arteries after $24 \mathrm{~h}$ of AngII treatment. $(\mathrm{n}=6), * P<.05$, $* * * P<.001$. The amount of targeted proteins was normalized to the total protein amount (Ponceau staining) present in each line was associated with impaired endothelium-dependent relaxation in resistance arteries. ${ }^{47}$ However, the alteration was more pronounced in L-NAME-treated $\mathrm{Opal}^{+/-}$mice than in L-NAME-treated WT mice, consistent with the higher blood pressure observed in L-NAME-treated $\mathrm{Opal}^{+/-}$mice. This higher hypertension was not associated with further hypertrophy in $\mathrm{Opal}^{+-}$mice compared to WT mice, this result may be due to a slower hypertension dependent remodeling in the $\mathrm{Opal}^{+/-}$mice which would be evidenced by a longer
L-NAME treatment. In our experiments, although the increase of collagen I is not significant, this variation is associated with an increase of collagen III in L-NAME-treated $\mathrm{Opal}^{+/-}$mice as demonstrated in supplemental data. Our results did not show that hypertension is the consequence of a deficiency of mitochondrial fusion but that alteration of mitochondrial fusion was an aggravating factor in hypertension. As described by Sarzy et al, the authors found that $\mathrm{Opal}^{+/-}$mouse displays a multi-systemic poly-degenerative phenotype, and a pre-mature 
FIGURE 8 Western blot examining Oxphos protein level in whole mesenteric arteries from normotensive and hypertensive mice. $(\mathrm{n}=6), * P<.05$, *** $P<.001$. The amount of targeted proteins was normalized to the total protein amount (Ponceau staining) present in each line

\section{Oxphos (MA)}
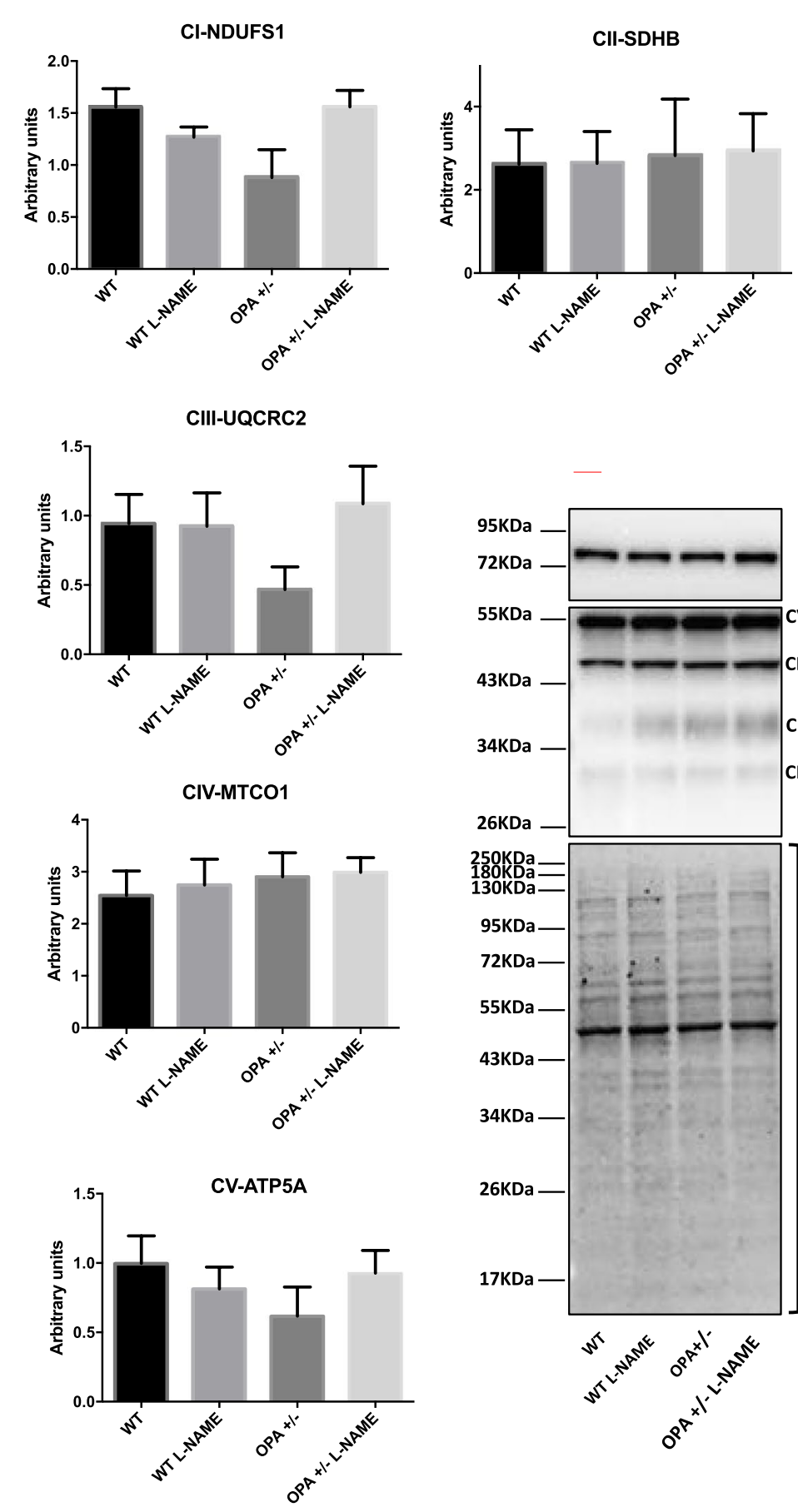

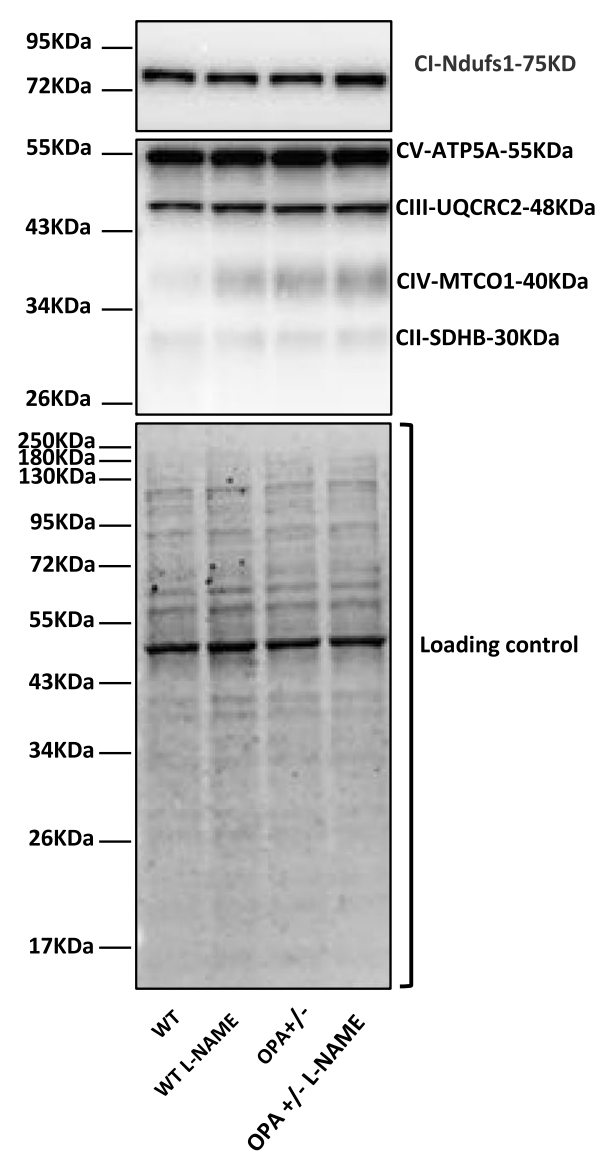

age-related mitochondrial supercomplex instability preceding degeneration and cell death. ${ }^{24}$ Indeed, it is well known that, in aging, vascular wall stiffness is increased. ${ }^{48}$ All these arguments could explain the excessive increase in blood pressure in $\mathrm{Opal}^{+/-}$hypertensive mice.

Previous studies have shown that endothelium dysfunction occurs before organ damage in hypertension. ${ }^{49}$ Chronic impairment in NO-mediated endothelium-dependent dilation and low-grade inflammation facilitate the maintenance of elevated peripheral resistance and promote hypertension development. ${ }^{50,51}$ Nevertheless, a recent study has compared plethysmography analysis using the tail cuff method to telemetry. It has demonstrated that the amplitude of the rise in pressure in mice is the same whether it is measured using plethysmography or telemetry, even though basal blood pressure is better measured with telemetry. ${ }^{52}$

Endothelial dysfunction in cardiovascular pathologies is usually associated with increased ROS production 


\section{OPA1 (VSMCs MA primary culture)}

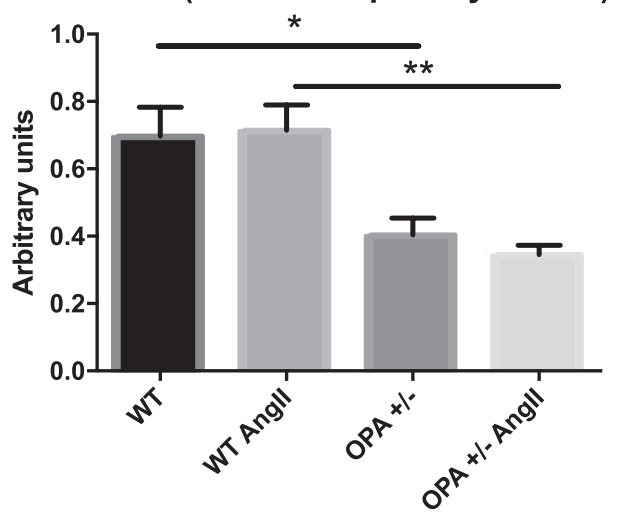

OPA1-L (VSMCs MA primary culture)

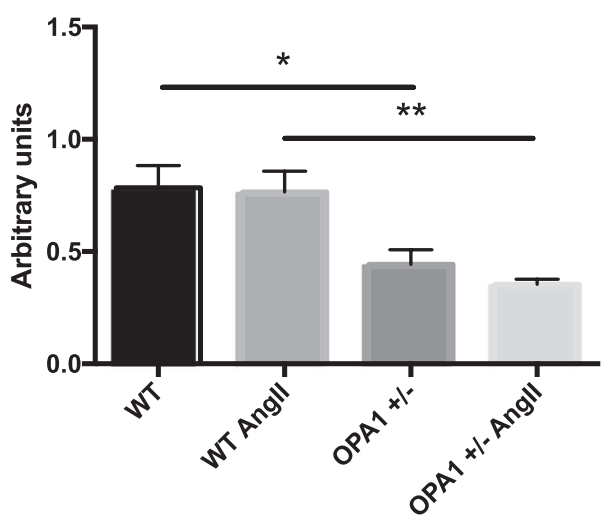

OPA1-s (VSMCs MA primary culture)

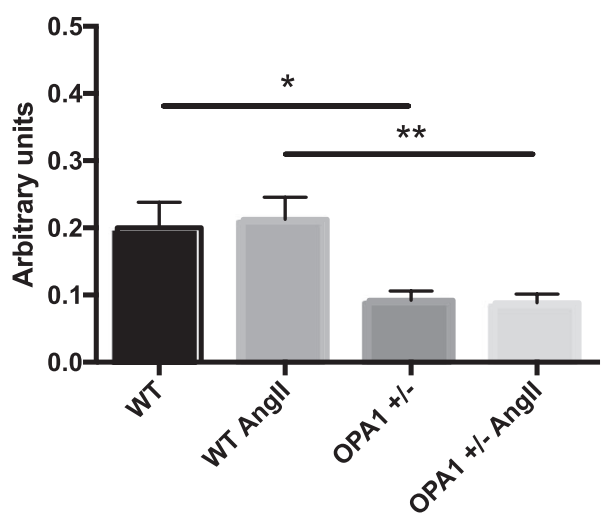

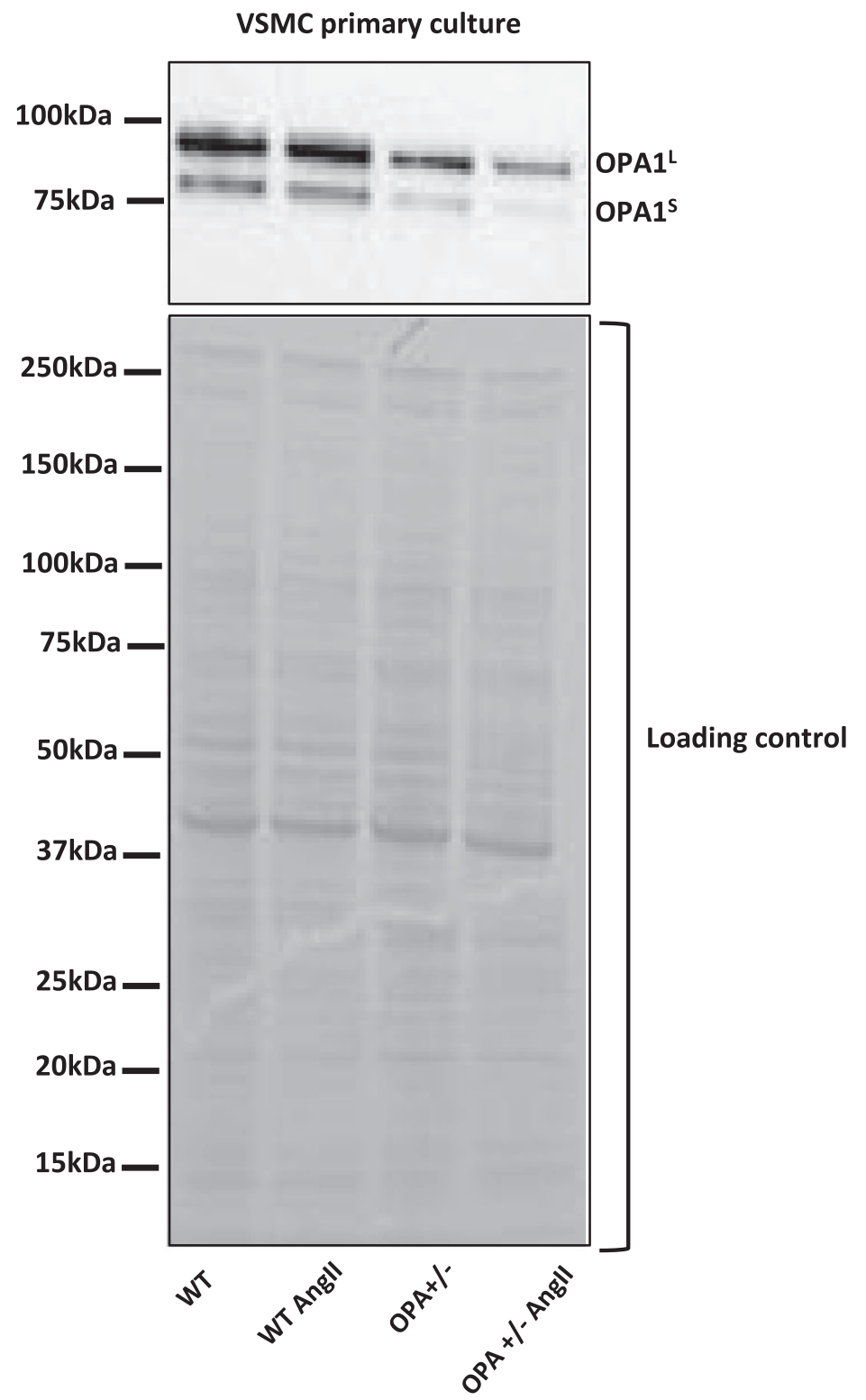

F I G URE 9 Western blot examining OPA1 protein and OPA1s and OPA1L level in primary VSMCs isolated from mesenteric arteries after $24 \mathrm{~h}$ of AngII. $(\mathrm{n}=6),{ }^{*} P<.05, * * * P<.001$. The amount of targeted proteins was normalized to the total protein amount (Ponceau staining) present in each line

which inactivates NO released from endothelial cells. ${ }^{53}$ In agreement, DHE staining showed a significantly increased ROS level in L-NAME-treated $\mathrm{Opal}^{+/-}$mice compared to L-NAME-treated WT mice, suggesting that ROS reduced endothelium (NO)-mediated relaxation in both groups and this effect was significantly more pronounced in
L-NAME-treated $\mathrm{Opal}^{+/-}$mice than in L-NAME-treated WT mice.

We also observed that SOD1 level was significantly lower in L-NAME-treated $\mathrm{Opal}^{+/-}$mice than in WT mice and SOD2 higher in L-NAME-treated $\mathrm{Opal}^{+/-}$mice than in WT mice, showing an imbalance of the oxidative stress. Despite 
FIGURE 10 Western blot examining OPA1 protein and OPA1s and OPA1L level in mesenteric arteries from normotensive and hypertensive mice. $(\mathrm{n}=6), * P<.05$, $* * * P<.001$. The amount of targeted proteins was normalized to the total protein amount (Ponceau staining) present in each line

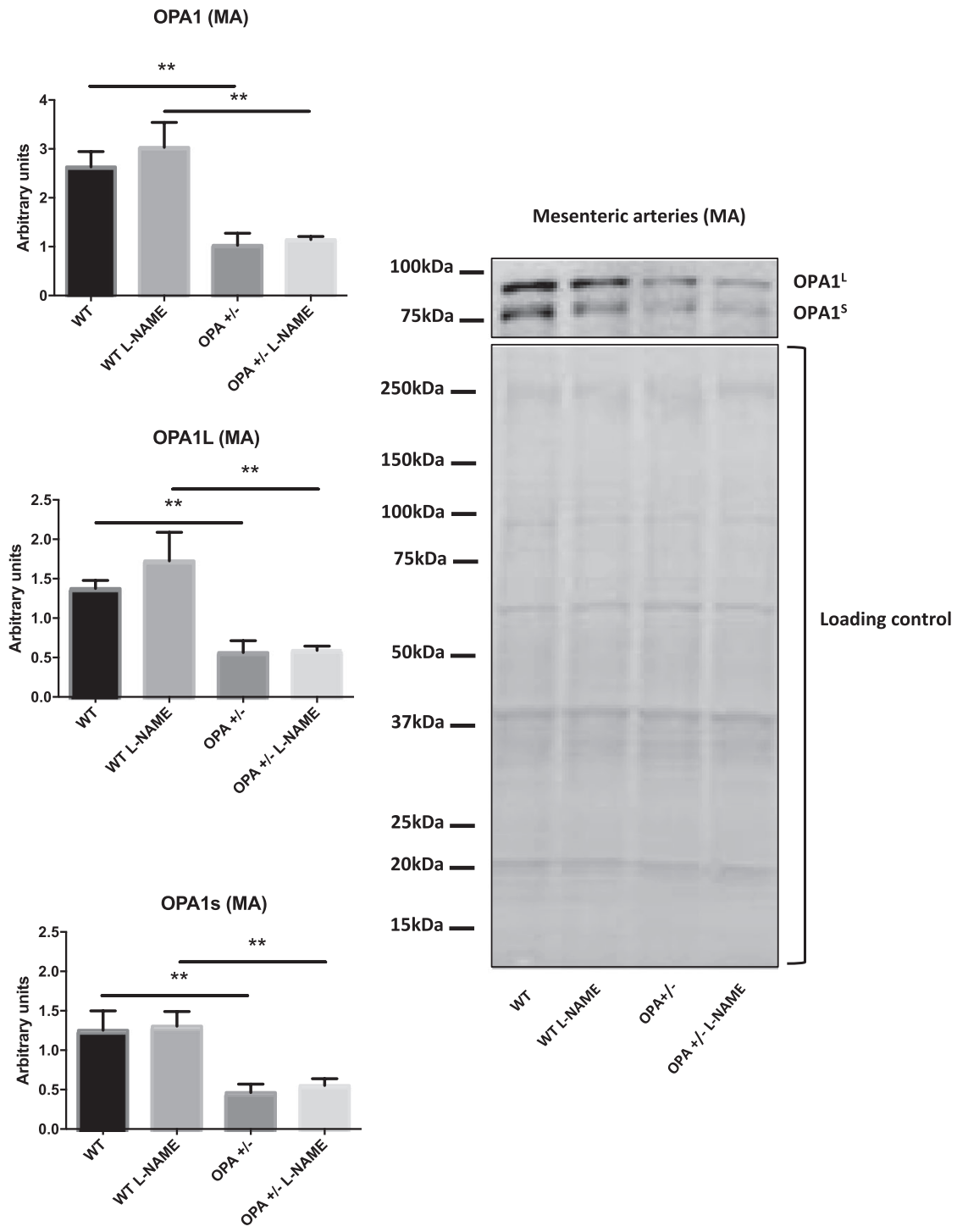

this higher SOD2 protein level trying a compensatory effect, oxidative stress (DHE and mitosox) stayed significantly higher in L-NAME-treated $\mathrm{Opal}^{+/-}$mice vs WT mice and subsequently leads to a more severe endothelium dysfunction in L-NAME-treated $\mathrm{Opal}^{+/-}$mice. Otherwise, there was no significant difference in expression level of eNOS between L-NAME-treated WT mice and L-NAME-treated $\mathrm{Opal}^{+-}$mice. Thus, the more pronounced impairment in endothelium-dependent relaxation in L-NAME-treated $\mathrm{Opal}^{+/-}$mice was not related to a reduced NO synthesis but to NO scavenging by ROS.

$\mathrm{Nrfl}$ is critical for mitochondrial biogenesis and for the regulation of respiratory genes. Tfam is an essential activator of mtDNA transcription and replication. Changes in Nrfl and Tfam expression could generally affect mitochondrial functionality and encoded in mtDNA. ${ }^{33}$ In the present study, we observed an up-regulation of $\mathrm{Nrfl}$ in L-NAMEtreated $\mathrm{Opal}^{+/-}$mice and up-regulation of Tfam in $\mathrm{Opal}^{+/-}$ mice compared to WT mice. These results show that Opal influence Tfam expression in normal condition and Nrfl expression during hypertension. Besides, up-regulation of $M f n 1$ but not of $\mathrm{Mfn} 2$ in L-NAME-treated $\mathrm{Opal}^{+/-}$mice suggests a compensatory process in the control of mitochondrial fusion due to Opal deficiency in these mice.

Finally, Oxphos complex western blot analysis showed that no significant difference was found in primary VSMCs and in mouse mesenteric arteries. These results could demonstrate a potential difference of complex expression but not activity, in agreement with Le Page et al who characterized mitochondrial respiration in $\mathrm{Opal}^{+/-}$and WT mice by measuring the respirations of complex I, II and IV without significant difference. ${ }^{23}$ Although the oxphos components showed no difference in protein levels, this did not mean that the mitochondrial membrane potential, and hence ATP or ROS production were not altered by these enzymes. Furthermore, no significant difference, with or without hypertension, was found in the expression of OPA1 long and short forms, suggesting a possible change of 
location of the OPA1 short form to be more active. Vascular cells (ECs and VSMCs) are exposed to blood pressure and shear stress. Hypertension induces mechanical fluctuations of pressure, applied to VSMCs, which could influence ATP and ROS production. ${ }^{54}$ On the other hand, the myocardium is also subjected to a variety of forces during each contraction, such as stretch, afterload, and shear stress, and adapts to those mechanical stimuli. The interaction between mitochondria and sarcomere directly affects cardiomyocyte excitation-contraction and is also involved in mechano-transduction through the cytoskeletal proteins and the sarcoplasmic reticulum. Mitochondria adapt their structure and activity by sensing mechanical forces in the environment and, within a dynamic organ such as the heart, it contributes to calcium homeostasis. ${ }^{55}$ Taken together, these results suggest that Opal deficiency affects in vivo response to high blood pressure via the induction of an excessive oxidative stress probably due to an altered mitochondrial function demonstrated by a hyper-fragmentation of the mitochondria.

In conclusion, down-regulation of Opal has no obvious impact on baseline vascular tone and structure, but in our Opal haploinsufficiency model, it aggravates endothelial dysfunction during hypertension and decrease the possibility to normalize tensile stress due to high blood pressure by hypertrophy of the vessel wall; an effect which might explain the increase in blood pressure in $\mathrm{Opal}^{+/-}$mice. Taken together, these data suggest for the first time that OPAl, a regulator of mitochondrial fusion and function, plays a protective role in blood vessels in stress conditions.

\section{ACKNOWLEDGMENTS}

We thank the SCIAM (Service commun d'Imageries et d'Analyses Microscopiques) for Electronic microscopy analysis and the SCAHU (Service Commun d'Animalerie Hospitalo-Universitaire) of the University of Angers.

\section{CONFLICT OF INTEREST}

None declared.

\section{AUTHOR CONTRIBUTIONS}

L. Loufrani designed the protocol, obtained grants, researched data, wrote the manuscript, contributed to discussion, and edited the manuscript. P. Robert, P.M.C. Nguyen, C. Grenier, A. Chevrollier, M. Munier, T. Champin, E. Lelièvre, E. Sarzi, L. Grimaud, E. Vessières, C. Proux, and A. Richard performed the experiments; S. Henni, D. Prunier, P. Reynier, G. Lenaers, C. Fassot, and D. Henrion contributed to discussion and reviewed the manuscript. All authors have approved the final version of the manuscript.

\section{ORCID}

Laurent Loufrani (D) https://orcid.org/0000-0003-3397-2335

\section{REFERENCES}

1. Touyz RM, Schiffrin EL. Reactive oxygen species in vascular biology: implications in hypertension. Histochem Cell Biol. 2004;122:339-352.

2. Kluge MA, Fetterman JL, Vita JA. Mitochondria and endothelial function. Circ Res. 2013;112:1171-1188.

3. Liu Y, Li H, Bubolz AH, Zhang DX, Gutterman DD. Endothelial cytoskeletal elements are critical for flow-mediated dilation in human coronary arterioles. Med Biol Eng Comput. 2008;46:469-478.

4. Mironov SL, Ivannikov MV, Johansson M. [Ca2+]i signaling between mitochondria and endoplasmic reticulum in neurons is regulated by microtubules. From mitochondrial permeability transition pore to Ca2+-induced Ca2 + release. J Biol Chem. 2005;280:715-721.

5. Katakam PV, Wappler EA, Katz PS, et al. Depolarization of mitochondria in endothelial cells promotes cerebral artery vasodilation by activation of nitric oxide synthase. Arterioscler Thromb Vasc Biol. 2013;33:752-759.

6. MacVicar T, Langer T. OPA1 processing in cell death and disease - the long and short of it. J Cell Sci. 2016;129:2297-2306.

7. Frezza C, Cipolat S, Martins de Brito O, et al. OPA1 controls apoptotic cristae remodeling independently from mitochondrial fusion. Cell. 2006;126:177-189.

8. Patten DA, Wong J, Khacho M, et al. OPA1-dependent cristae modulation is essential for cellular adaptation to metabolic demand. EMBO J. 2014;33:2676-2691.

9. Olichon A, Baricault L, Gas N, et al. Loss of OPA1 perturbates the mitochondrial inner membrane structure and integrity, leading to cytochrome c release and apoptosis. J Biol Chem. 2003;278:7743-7746.

10. Fulop L, Szanda G, Enyedi B, Varnai P, Spat A. The effect of OPA1 on mitochondrial $\mathrm{Ca}^{2+}$ signaling. PLoS One. 2011;6:e25199.

11. Tang S, Le PK, Tse S, Wallace DC, Huang T. Heterozygous mutation of Opa1 in Drosophila shortens lifespan mediated through increased reactive oxygen species production. PLoS One. 2009;4:e4492.

12. Chen H, Chomyn A, Chan DC. Disruption of fusion results in mitochondrial heterogeneity and dysfunction. J Biol Chem. 2005;280:26185-26192.

13. Kao SH, Yen MY, Wang AG, Yeh YL, Lin AL. Changes in mitochondrial morphology and bioenergetics in human lymphoblastoid cells with four novel OPA1 mutations. Invest Ophthalmol Vis Sci. 2015;56:2269-2278

14. Yarosh W, Monserrate J, Tong JJ, et al. The molecular mechanisms of OPA1-mediated optic atrophy in Drosophila model and prospects for antioxidant treatment. PLoS Genet. 2008;4:e6.

15. Puddu P, Puddu GM, Cravero E, Pascalis S, Muscari A. The putative role of mitochondrial dysfunction in hypertension. Clin Exp Hypertens. 2007;29:427-434.

16. Vishnyakova PA, Volodina MA, Tarasova NV, et al. Mitochondrial role in adaptive response to stress conditions in preeclampsia. Sci Rep. 2016;6:32410.

17. Jin HS, Sober S, Hong KW, et al. Age-dependent association of the polymorphisms in the mitochondria-shaping gene, OPA1, with blood pressure and hypertension in Korean population. Am J Hypertens. 2011;24:1127-1135.

18. Dai Y, Weinreb RN, Kim KY, et al. Inducible nitric oxide synthasemediated alteration of mitochondrial OPA1 expression in ocular hypertensive rats. Invest Ophthalmol Vis Sci. 2011;52:2468-2476.

19. Lin YY, Hong Y, Yu SH, et al. Antiapoptotic and mitochondrial biogenetic effects of exercise training on ovariectomized hypertensive rat hearts. J Appl Physiol. 126, 1661-1672. 
20. Tang Y, Mi C, Liu J, Gao F, Long J. Compromised mitochondrial remodeling in compensatory hypertrophied myocardium of spontaneously hypertensive rat. Cardiovasc Pathol. 2014;23:101-106.

21. Lahera V, de Las Heras N, Lopez-Farre A, Manucha W, Ferder L. Role of mitochondrial dysfunction in hypertension and obesity. Curr Hypertens Rep. 2017;19:11.

22. Ong SB, Subrayan S, Lim SY, Yellon DM, Davidson SM, Hausenloy DJ. Inhibiting mitochondrial fission protects the heart against ischemia/reperfusion injury. Circulation. 2010;121:2012-2022.

23. Le Page S, Niro M, Fauconnier J, et al. Increase in cardiac ischemia-reperfusion injuries in Opa1+/- mouse model. PLoS One. 2016;11:e0164066.

24. Sarzi E, Angebault C, Seveno M, et al. The human OPA1delTTAG mutation induces premature age-related systemic neurodegeneration in mouse. Brain. 2012;135:3599-3613.

25. Berger JM, Vaillant N, Le May C, et al. PCSK9-deficiency does not alter blood pressure and sodium balance in mouse models of hypertension. Atherosclerosis. 2015;239:252-259.

26. Codron P, Cassereau J, Vourc'h P, et al. Primary fibroblasts derived from sporadic amyotrophic lateral sclerosis patients do not show ALS cytological lesions. Amyotroph Lateral Scler Frontotemporal Degener. 2018;19:446-456.

27. Chevrollier A, Cassereau J, Ferré M, et al. Standardized mitochondrial analysis gives new insights into mitochondrial dynamics and OPA1 function. Int J Biochem Cell Biol. 2012;44:980-988.

28. Cousin M, Custaud MA, Baron-Menguy C, et al. Role of angioten$\sin \mathrm{II}$ in the remodeling induced by a chronic increase in flow in rat mesenteric resistance arteries. Hypertension. 2010;55:109-115.

29. Loufrani L, Matrougui K, Li Z, et al. Selective microvascular dysfunction in mice lacking the gene encoding for desmin. FASEB $J$. 2002;16:117-119.

30. Bouvet C, Belin de Chantemele E, Guihot AL, et al. Flow-induced remodeling in resistance arteries from obese Zucker rats is associated with endothelial dysfunction. Hypertension. 2007;50:248-254.

31. Retailleau K, Belin de Chantemele EJ, Chanoine S, et al. Reactive oxygen species and cyclooxygenase 2-derived thromboxane A2 reduce angiotensin II type 2 receptor vasorelaxation in diabetic rat resistance arteries. Hypertension. 2010;55:339-344.

32. Piantadosi CA, Suliman HB. Mitochondrial transcription factor A induction by redox activation of nuclear respiratory factor 1. J Biol Chem. 2006;281:324-333.

33. Kelly DP, Scarpulla RC. Transcriptional regulatory circuits controlling mitochondrial biogenesis and function. Genes Dev. 2004;18:357-368.

34. Bertholet AM, Millet AM, Guillermin O, et al. OPA1 loss of function affects in vitro neuronal maturation. Brain. 2013;136:1518-1533.

35. Caffin F, Prola A, Piquereau J, et al. Altered skeletal muscle mitochondrial biogenesis but improved endurance capacity in trained OPA1-deficient mice. J Physiol. 2013;591:6017-6037.

36. Chen L, Liu T, Tran A, et al. OPA1 mutation and late-onset cardiomyopathy: mitochondrial dysfunction and mtDNA instability. $J$ Am Heart Assoc. 2012;1:e003012.

37. Sun Y, Carretero OA, Xu J, et al. Lack of inducible NO synthase reduces oxidative stress and enhances cardiac response to isoproterenol in mice with deoxycorticosterone acetate-salt hypertension. Hypertension. 2005;46:1355-1361.

38. Chao de la Barca JM, Simard G, Sarzi E, et al. Targeted metabolomics reveals early dominant optic atrophy signature in optic nerves of Opa1delTTAG/+ mice. Invest Ophthalmol Vis Sci. 2017;58:812-820.

39. Olichon A, Landes T, Arnauné-Pelloquin L, et al. Effects of OPA1 mutations on mitochondrial morphology and apoptosis relevance to ADOA pathogenesis. J Cell Physiol. 2007;211:423-430.
40. Ribeiro MO, Antunes E, de Nucci G, Lovisolo SM, Zatz R. Chronic inhibition of nitric oxide synthesis. A new model of arterial hypertension. Hypertension. 1992;20:298-303.

41. Liu N, Wu J, Zhang L, et al. Hydrogen Sulphide modulating mitochondrial morphology to promote mitophagy in endothelial cells under high-glucose and high-palmitate. J Cell Mol Med. 2017;21:3190-3203.

42. Makino A, Scott BT, Dillmann WH. Mitochondrial fragmentation and superoxide anion production in coronary endothelial cells from a mouse model of type 1 diabetes. Diabetologia. 2010;53:1783-1794.

43. Formichi P, Radi E, Giorgi E, et al. Analysis of opa1 isoforms expression and apoptosis regulation in autosomal dominant optic atrophy (ADOA) patients with mutations in the opa1 gene. J Neurol Sci. 2015;351:99-108.

44. Piquereau J, Caffin F, Novotova M, et al. Down-regulation of OPA1 alters mouse mitochondrial morphology, PTP function, and cardiac adaptation to pressure overload. Cardiovasc Res. 2012;94:408-417.

45. Preti SC, Cunha V, Vassallo DV, Stefanon I. The superoxide dismutase mimetic, tempol, reduces the bioavailability of nitric oxide and does not alter L-NAME-induced hypertension in rats. Basic Clin Pharmacol Toxicol. 2005;29-34.

46. Kalliovalkama J, Jolma P, Tolvanen JP, et al. Arterial function in nitric oxide-deficient hypertension. Cardiovasc Res. 1999;42:773-782.

47. Dowell FJ, Henrion D, Duriez M, Michel JB. Vascular reactivity in mesenteric resistance arteries following chronic nitric oxide synthase inhibition in Wistar rats. Br J Pharmacol. 1996;117:341-346.

48. Lakatta EG, Levy D. Arterial and cardiac aging : major shareholders incardiovascular disease enterprises : Part I : aging arteries : a « set up »for vascular disease. Circulation. 2003;107:139-146.

49. Endemann DH, Schiffrin EL. Endothelial dysfunction. J Am Soc Nephrol. 2004;15:1983-1992.

50. Bautista LE. Inflammation, endothelial dysfunction, and the risk of high blood pressure: epidemiologic and biological evidence. $J$ Hum Hypertens. 2003;17:223-230.

51. Wei BR, Stauffer BL, Greiner J, DeSouza CA. Prehypertension is associated with impaired nitric oxide-mediated endothelium-dependent vasodilation in sedentary adults. Am J Hypertens. 2011;24:976-981.

52. Wilde E, Aubdool AA, Thakore P, et al. Tail-cuff technique and its influence on central blood pressure in the mouse. $J$ Am Heart Assoc. 2017;6:e05204.

53. Cai H, Harrison DG. Endothelial dysfunction in cardiovascular diseases: the role of oxidant stress. Circ Res. 2000;87:840-844.

54. Bartolák-Suki E, Suki B. Tuning mitochondrial structure and function to criticality by fluctuation-driven mechanotransduction. Sci Rep. 2020;10:407.

55. Caffarra Malvezzi C, Cabassi A, Miragoli M. Mitochondrial mechanosensor in cardiovascular diseases. Vasc Biol. 2020;2:R85-R92.

\section{SUPPORTING INFORMATION}

Additional Supporting Information may be found online in the Supporting Information section.

How to cite this article: Robert P, Nguyen PMC, Richard A, et al. Protective role of the mitochondrial fusion protein OPA1 in hypertension. The FASEB Journal. 2021;35:e21678. https://doi.org/10.1096/ fj.202000238RRR 